Final Report

FHWA/IN/JTRP-2005/21

\title{
STUDY OF SALT WASH WATER TOXICITY ON WASTEWATER TREATMENT
}

\author{
By \\ Mostafa F. Hashad \\ Graduate Research Assistant \\ School of Civil Engineering \\ Surabhi Sharma \\ Graduate Research Assistant \\ School of Civil Engineering \\ and \\ Loring F. Nies \\ Associate Professor of Civil Engineering \\ James E. Alleman \\ Professor of Civil Engineering \\ Joint Transportation Research Program \\ Project No. C-36-68R \\ File No. 4-7-18 \\ SPR-2625 \\ In Cooperation with the \\ Indiana Department of Transportation and \\ the Federal Highway Administration \\ U.S. Department of Transportation
}

The contents of this report reflect the views of the authors, who are responsible for the facts and the accuracy of the data presented herein. The contents do not necessarily reflect the official views or policies of the Indiana Department of Transportation. This report does not constitute a standard, specification or regulation.

Purdue University

West Lafayette, Indiana 47907

August 2006 


\section{Table of Contents}

1. Executive Summary v

1.1. Abstract v

1.2. Problem Statement 1

1.3. Objectives 3

1.4 Salinity Related Impact Issues 3

1.5 Cyanide Related Impact Issues 5

1.5.1 Expected Cyanide Concentrations 6

1.5.2 Standards for Effluent Cyanide in the State Of Indiana 7

1.6 Research Objectives 8

2. Introduction 9

2.1. Theoretical Background 9

2.2. Previous Research Activities 15

2.3. Proposed Research Approach 15

3. Materials and Methods 17

3.1. Sampling and Preparation 17

3.2. Apparatus and System Description 18

3.3. Experimental Setup 19

3.3.1. Scheme 1 19

3.3.2. Scheme 2 20

3.4 Wastewater Sample and its Characteristics 20

3.4.1 Chemical Oxygen Demand 21

3.4.2 Turbidity 24

3.4.3 Cyanide 25

4. Results and Discussions $\quad 27$

4.1 Respiromotry $\quad 27$

4.2 Cod Depletion Rate Impact Results 31

4.3 Turbidity Reduction Rate Impact Results 34

4.4 Cyanide Levels Present in INDOT's Salts 37

5. Conclusion 39

6. References 40 


\begin{tabular}{|c|c|c|c|c|}
\hline $\begin{array}{l}\text { 1. Report No. } \\
\text { FHWA/IN/JTRP-2005/21 }\end{array}$ & \multicolumn{2}{|c|}{ 2. Government Accession No. } & \multicolumn{2}{|c|}{ 3. Recipient's Catalog No. } \\
\hline \multirow{2}{*}{\multicolumn{3}{|c|}{$\begin{array}{l}\text { 4. Title and Subtitle } \\
\text { Study of Salt Wash Water Toxicity on Wastewater Treatment }\end{array}$}} & \multicolumn{2}{|l|}{$\begin{array}{l}\text { 5. Report Date } \\
\text { August } 2006\end{array}$} \\
\hline & & & \multicolumn{2}{|c|}{ 6. Performing Organization Code } \\
\hline \multicolumn{3}{|c|}{$\begin{array}{l}\text { 7. Author(s) } \\
\text { Mostafa Hashad, Surabhi Sharmi, Loring F. Nies, and James E. Alleman }\end{array}$} & \multicolumn{2}{|c|}{$\begin{array}{l}\text { 8. Performing Organization Report No. } \\
\text { FHWA/IN/JTRP-2005/21 }\end{array}$} \\
\hline \multirow{2}{*}{\multicolumn{3}{|c|}{$\begin{array}{l}\text { 9. Performing Organization Name and Address } \\
\text { Joint Transportation Research Program } \\
1284 \text { Civil Engineering Building } \\
\text { Purdue University } \\
\text { West Lafayette, IN 47907-1284 }\end{array}$}} & \multicolumn{2}{|l|}{ 10. Work Unit No. } \\
\hline & & & \multicolumn{2}{|c|}{$\begin{array}{c}\text { 11. Contract or Grant No. } \\
\text { SPR-2625 }\end{array}$} \\
\hline \multirow{2}{*}{\multicolumn{3}{|c|}{$\begin{array}{l}\text { 12. Sponsoring Agency Name and Address } \\
\text { Indiana Department of Transportation } \\
\text { State Office Building } \\
100 \text { North Senate Avenue } \\
\text { Indianapolis, IN } 46204\end{array}$}} & \multicolumn{2}{|c|}{$\begin{array}{l}\text { 13. Type of Report and Period Covered } \\
\text { Final Report }\end{array}$} \\
\hline & & & \multicolumn{2}{|c|}{ 14. Sponsoring Agency Code } \\
\hline \multicolumn{5}{|c|}{$\begin{array}{l}\text { 15. Supplementary Notes } \\
\text { Prepared in cooperation with the Indiana Department of Transportation and Federal Highway Administration. }\end{array}$} \\
\hline \multicolumn{5}{|c|}{ 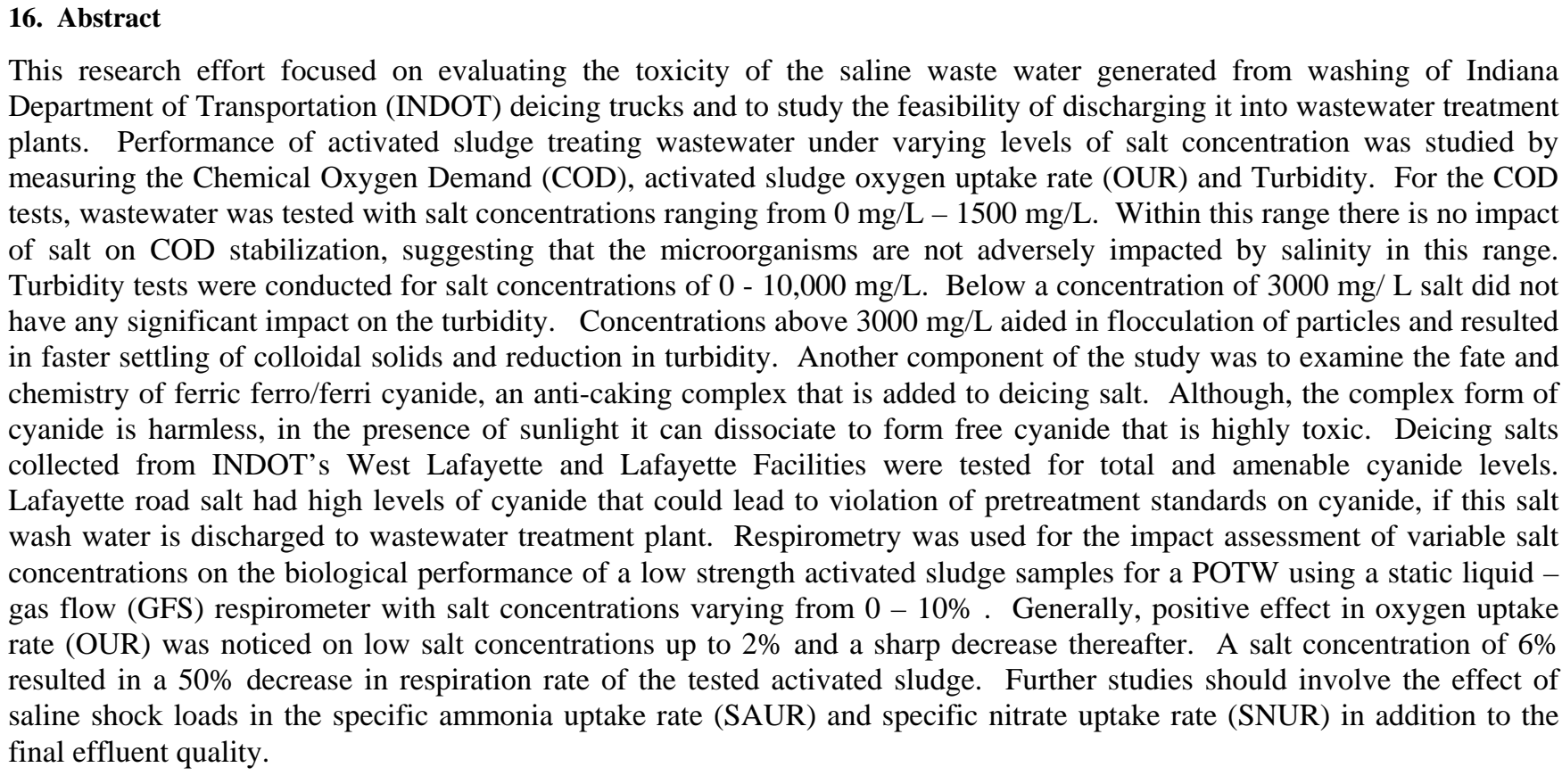 } \\
\hline \multicolumn{2}{|c|}{$\begin{array}{l}\text { 17. Key Words } \\
\text { Activated sludge, Deicing salt, Snow Control, Oxygen } \\
\text { Uptake Rate, Saline Wastewater, Respirometry }\end{array}$} & \multicolumn{3}{|c|}{$\begin{array}{l}\text { 18. Distribution Statement } \\
\text { No restrictions. This document is available to the public through the } \\
\text { National Technical Information Service, Springfield, VA } 22161\end{array}$} \\
\hline 19. Security Classif. (of this report) & 20. Security Class & is page) & 21. No. of Pages & 22. Price \\
\hline
\end{tabular}




\section{List of Figures}

Figure 2.1 Phase Diagram of Sodium Chloride 10

Figure 2.2 Relationship Respiration, Substrate Utilization and Growth.

Figure 3.1 Deicing Salt Samples 17

Figure 3.2 N-Con Comput-Ox Wb-400 Respirometer 18

Figure 3.3 Calibration Curve for Cod Stabilization 22

Figure 4.1 Sample Respirogram (Test 0329) 28

Figure 4.2 Scheme 1 Testing Results 29

Figure 4.3 Scheme 2 Testing Results 30

Figure 4.4 Cod Stabilization - Experimental Results 31

Figure 4.5 Cod Stabilization - Regression Analysis 32

Figure 4.6 Effect of Low Salinity On Turbidity 34

Figure 4.7 Effect of High Salinity On Turbidity 35

\section{List of Tables}

Table 2.1 Eight Basic Respirometers Classification 14

Table 3.1 Dilution Factors for Sample Preparation (Scheme 2) 20

Table 3.2 Dilution Series for Cod Standards 22

Table 3.3 Exposure Time for Salt Samples 26

Table 4.1 Scheme 1 Testing Results $\quad 29$

Table 4.2 Scheme 2 Testing Results $\quad 30$

Table 4.3 Experimental Results for Cyanide $\quad 37$

Table 4.4 Mass of Inerts in Samples Given for Testing 37 


\section{ACKNOWLEDGEMENT}

The authors acknowledge the assistance of Dr. Changhe Xiao, Environmental Lab Manager, for his help and ultimate support rendered in the experimental work. 


\section{EXECUTIVE SUMMARY}

\subsection{Abstract}

This research effort focused on evaluating the toxicity of the saline waste water generated from washing of Indiana Department of Transportation (INDOT) deicing trucks and to study the feasibility of discharging it into wastewater treatment plants. Performance of activated sludge treating wastewater under varying levels of salt concentration was studied by measuring the Chemical Oxygen Demand (COD), activated sludge oxygen uptake rate (OUR) and Turbidity. For the COD tests, wastewater was tested with salt concentrations ranging from $0 \mathrm{mg} / \mathrm{L}-1500$ $\mathrm{mg} / \mathrm{L}$. Within this range there is no impact of salt on COD stabilization, suggesting that the microorganisms are not adversely impacted by salinity in this range. Turbidity tests were conducted for salt concentrations of $0-10,000 \mathrm{mg} / \mathrm{L}$. Below a concentration of $3000 \mathrm{mg} / \mathrm{L}$ salt did not have any significant impact on the turbidity. Concentrations above $3000 \mathrm{mg} / \mathrm{L}$ aided in flocculation of particles and resulted in faster settling of colloidal solids and reduction in turbidity. Another component of the study was to examine the fate and chemistry of ferric ferro/ferri cyanide, an anti-caking complex that is added to deicing salt. Although, the complex form of cyanide is harmless, in the presence of sunlight it can dissociate to form free cyanide that is highly toxic. Deicing salts collected from INDOT's West Lafayette and Lafayette Facilities were tested for total and amenable cyanide levels. Lafayette road salt had higher levels of cyanide than West Lafayette. Respirometry was used for the impact assessment of variable salt concentrations on the biological performance of a low strength activated sludge samples for a POTW using a static liquid - gas flow (GFS) respirometer with salt concentrations varying from $0-10 \%$. Generally, a positive effect in oxygen uptake rate (OUR) was noticed from low salt concentrations up to $2 \%$. Based on typical wash water volumes from INDOT maintenance facilities, salt concentrations would be substantially diluted upon discharge to a POTW and produce no adverse effects whatsoever.

Keywords: Activated sludge, Deicing salt, Snow Control, Oxygen Uptake Rate, Saline Wastewater, Respirometry 


\subsection{Problem Statement}

The problem addressed in this research phase is the anticipated impact of saline shock loads resulting from washing and cleaning activities of INDOT deicing trucks on the performance of POTWs. Most of Indiana's POTWs prohibits the discharge of these saline brines into their facilities, yet little information is available with regard to the possible effect of this discharged wastes into wastewater treatment facilities.

Salt is the most commonly used deicing chemical in the United States. It is spread at a rate of approximately 10 million tons per year (Transportation Research Board, 1991). Salt melts ice by depressing the freezing point of water. The freezing point of the solution is lowered until the salt concentration reaches about 25 percent. This threshold concentration marks the eutectic point, at which the freezing temperature of the solution can no longer be lowered, and the addition of more salt has no additional ice-melting effect. The eutectic temperature for salt solution is $-21^{\circ}$ $\mathrm{C}\left(-6^{\circ} \mathrm{F}\right)$. If applied properly, small amounts of salt usually produce partial melting and flowing brines that break the bond between pavement and ice and thereby allow accumulations to be removed by the action of traffic or plowing (Transportation Research Board, 1991).

When salt dissolves in water, the freezing point is depressed in proportion to the concentration of ions in solution. Because sodium chloride $(\mathrm{NaCl})$ is very soluble in water and yields a large number of ions per unit weight, it is especially effective as a freezing point depressant, or icemelter $\left(\mathrm{NaCl}=\mathrm{Na}^{+}+\mathrm{Cl}^{-}\right)$. However, at pavement temperatures below $-12^{\circ} \mathrm{C}$ sodium chloride is not as effective and highway agencies rely more on sanding or salt mixed with calcium chloride $\left(\mathrm{CaCl}_{2}\right)$ for deicing. Cyanide complexes, such as ferric ferrocyanide $\mathrm{Fe}_{4}\left(\mathrm{Fe}(\mathrm{CN})_{6}\right)_{3}$, are added to chloride salts to keep the deicing salt free-flowing during storage and application.

Indiana Department of Transportation uses sodium chloride in large quantities for its deicing operations. The average annual salt loading on state highways in Indiana is approximately 9.0 tons/lane-mile (Transportation Research Board, 1991).

Salts applied to roadways can enter air, soil, groundwater, and surface water from direct or snowmelt runoff, release from surface soils, and / or wind-borne spray. Their accumulation and 
persistence in soils and watersheds pose risks to ecosystems and to water quality. High concentrations of road salts are believed to have adverse effects on roadside vegetation, wildlife habitats, water and soil (Transportation Research Board, 1991). Apart from surface runoff and infiltration, the washing and cleaning operations of the vehicles and storage areas used during the deicing operations also generate saline wastewater.

Currently, when INDOT deicing trucks are washed, the wash wastewater is collected and reused for deicing after volume reduction or is stored off-site in ditches. Where available, discharge of wash wastewater to local POTWs would provide an additional cost-effective and simpler option for disposal. However, most Indiana POTWs would not allow discharge of the deicing wash wastewater to their treatment plants due to their concern about the potential adverse effects of salinity on biological treatment processes. Very little is known about the toxicity of modern deicing mixtures (calcium chloride $\left(\mathrm{MgCl}_{2}\right)$, magnesium chloride $\left(\mathrm{MgCl}_{2}\right)$, or calcium acetate $\left(\mathrm{Ca}\left(\mathrm{CH}_{3} \mathrm{COO}\right)_{2}\right)$ etc.) to microorganisms in wastewater treatment plants. Few studies that have been published on the effect of standard sodium chloride on aerobic activated sludge treatment processes. They demonstrate that no decrease in wastewater treatment performance is observed at concentrations approaching 3\% $\mathrm{NaCl}(\mathrm{w} / \mathrm{w})$ (Hamoda et al., 1991).

Apart from salinity related effects, another issue of concern is the cyanide complexes that are present in the road salt. These chemicals are used as anti-caking agents (at 20 to $150 \mathrm{ppm}$ dosage levels) in road salts used by INDOT operations, primarily in the following two forms: ferric ferrocyanide (Prussian blue) $\mathrm{Fe}_{4}\left(\mathrm{Fe}(\mathrm{CN})_{6}\right)_{3}$ and ferric ferricyanide, $\mathrm{Fe}_{3}\left(\mathrm{Fe}(\mathrm{CN})_{6}\right)_{3}$.

These complexes can be photolyzed to release approximately $25 \%$ toxic cyanide ions. If the salt wash wastewater is discharged to the POTWs, this might impose a regulatory compliance problem with respect to the facility's effluent National Pollution Discharge Elimination Standards (NPDES) permit. 


\subsection{OBJECTIVES}

The main objective of this project is to develop a better understanding of the potential inhibitory action of saline brines resulting from INDOT wash water on the biological treatment processes in local POTWs in order to consider the feasibility of disposal of saline wash water to these systems.

For this phase of the project, respirometry was used to analyze the kinetics of biodegradation of wastewater constituents in activated sludge samples in response to salt water shock loads.

\subsection{SALINITY RELATED IMPACT ISSUES}

There have been contradicting reports in the literature about the effects that salinity has on the performance of microorganisms in biological processes treating wastewater. Some investigators claim that high salinity or shock load of sodium chloride would adversely affect organic removal efficiency and sludge settleability of the treatment processes. Others have reported that constant application of sodium chloride to biological treatment systems does not upset the organic matter removal efficiency and results in good flocculation of the biomass. Acclimation of biomass and the level of salt content used are important factors that should be considered when comparing these different observations. (Hamoda et al., 1995)

The carbon and nitrogen removal efficiency of a system can be maintained if it is appropriately acclimatized (Panswad et al., 1999). Organic matter removal efficiency can also be improved by addition of halophilic organisms that can sustain well in highly saline environments. It has been found that phosphorus-accumulating bacteria are more sensitive to the high salinity than carbon bacteria, nitrifiers, and denitrifiers. Nitrogen removal efficiency is not affected much until a salinity level of $4000 \mathrm{mg} / \mathrm{L}$. However, the phosphorus removal efficiency decreases even at that relatively lower salinity level (Nugul et al., 1999).

It has been found that addition of salts, in the form of sodium chloride, increases the respiration rate of microorganisms until a specific salt concentration is reached, thereafter a decrease is observed. It has been investigated that sodium chloride concentrations of $0.1,0.6$ and $1.2 \mathrm{~g} / \mathrm{L}$ 
stimulate the aggregation of resuspended cells of Zooglea ramigera, with the highest concentration being the most effective (Hamoda et al., 1995).

Activated sludge flocs consist of aggregates, which are made up of primary particles. These primary particles are compact and can retain their structures under shear or compaction. The floc, however, is lose and weak and can be broken easily. Most flocs tend to break down and the aggregates become the elementary entities that control the processes of coagulation, flocculation and settling (Lee et al., 1999).

Destabilization is the process in which particles in a stable suspension are modified to increase their tendency to attach to one another. After destabilization, for aggregation to take place, particles need to be transported toward one another. Double layer compression is one form of colloidal destabilization (AWWA, 1999). The double-layer around the particle consists of ions attached loosely to the solid surface (called fixed layer or Stern layer). Beyond this layer the diffuse layer (or Guoy) exists where ions are free to move. When particles are approaching each other in the Guoy layer, they electrostatically repel each other, thus keeping particles apart; resulting in a stable suspension. As the ionic strength of the solution increases, the Guoy layer is compressed and particles come closer to each other. When distances between particles decrease, the vander Waals forces of attraction overcome the electrostatic forces of repulsion. As a result, the particles tend to attract toward each other, forming flocs and making the suspension unstable (Ritvo et al., 2003). Electrolytes such as sodium chloride are known to aid in double layer compression (AWWA, 1999). The presence of ions with opposite charge enhances flocculation by bridging among the particles and helping them form aggregates which eventually flocculate (Lee et al., 1999). Destabilization by double-layer compression improves as the salt concentrations approach that of seawater (AWWA, 1999).

It has been reported that a critical salinity concentration of approximately $1-2 \%(\mathrm{w} / \mathrm{w})$ exists at which the mechanism governing bacteria aggregation and stability of sludge flocs changes. Below this critical concentration, double layer compression or the hydrophobic interactions improve inter bacterial interactions. But as the concentration of salinity exceeds this limit, the tendency of bacteria aggregation or adsorption decreases. This could be explained by the 
phenomena of ion exchange by which $\mathrm{Na}^{+}$ions replace the $\mathrm{Ca}^{2+}$ ions. $\mathrm{Ca}^{+2}$ ions play an important role in bridging to help in flocculation. Ion exchange replacement of $\mathrm{Ca}^{+2}$ ions could lead to destabilization of the sludge flocs. It has been proposed that conformation change of extra cellular polymer may also cause sludge flocs to disintegrate (Lee et al., 1999).

It should be noted that saline wash water from the City of West Lafayette truck maintenance facility is routinely discharged to the West Lafayette wastewater treatment plant with no adverse effects. The wash water is passed through an oil-water separator prior to discharge to the treatment plant (Downey, Personal Communication, 2006).

\subsection{CYANIDE RELATED IMPACT ISSUES}

There are several factors which should be addressed in terms of assessing the cyanide issue and characterizing its potential impact on desired discharge of salt truck wash waters into municipal sewer systems. A preliminary literature review completed on this topic shows that iron cyanide complexes undergo rapid photolysis in the presence of sunlight yielding free hydrogen cyanide that is toxic (Theis et al., 1994, Langen et al., 2006). It has also been reported that iron cyanide complexes will adsorb to solids and precipitate from solution under conditions typically found in aerobic wastewater (Rennert, T. and T. Mansfeldt 2005). Transportation Research projects examining the environmental impacts of road salt use in Minnesota and New York have found no conclusive evidence of adverse effects of cyanide anti-caking agents on plants or microorganisms (Langen et al., 2006; Anderson et al., 2000). It is expected that adsorption, dilution, volatilization and other chemical transformations of cyanide complexes would ameliorate adverse environmental impacts (Paschka et al., 1999). However, no actual field studies have yet been performed to monitor cyanide levels along roadsides or in wastewater treatment plant effluents (Ramakrishna and Viraraghavan 2005). The West Lafayette wastewater

treatment plant does not monitor cyanide levels in their influent or effluent (Downey, Personal Communication, 2006). 


\subsubsection{Estimated Cyanide Concentrations}

The following calculations estimate the magnitude of cyanide presence both within the original salt, the expected truck wash water, and the likely levels of cyanide entering a municipal wastewater treatment facility:

\section{CYANIDE PRESENT IN THE ORIGINAL ROAD SALT:}

- About 30-124 mg/kg or 27.2-112.5 g/ton of anti-caking agent added to salt (Langen et al., 2006).

- Percent by weight of $\mathrm{CN}$ - in ferric ferricyanide $=58.3 \%$. Therefore, range of cyanide present in salt $=15.9-65.6 \mathrm{~g} \mathrm{CN}^{-} /$ton.

\section{CYANIDE PRESENT IN THE INDOT TRUCK WASH WATER:}

(Per truck washed)

- Washing a truck with pressure sprayer at a rate of $5 \mathrm{gal} / \mathrm{min}$ uses around 175 gallons (Alleman et al., 2004).

- Total wash water for one truck $=662.4$ liters

- Average salt concentration in truck wash water $=41.2 \mathrm{~g} / \mathrm{L}$ (Alleman et al., 2004).

- Therefore, maximum estimated concentration of cyanide in an average batch of wash water $=5.1 \mathrm{mg} \mathrm{CN}^{-} / \mathrm{L}$

\section{CYANIDE PRESENT IN THE RECEIVING WASTEWATER TREATMENT FACILITY}

(Assume a typical POTW flow of 1 MGD or 694 gallons per minute)

- The amount of flow required to dilute $\mathrm{CN}^{-}$maximum concentrations to below 5 $\mathrm{ug} / \mathrm{L}=174,832$ gallons

- Therefore, an average truck wash could be discharged into a typical POTW every 4.2 hours without exceeding $5 \mu \mathrm{g} / \mathrm{L}$ total $\mathrm{CN}^{-}$.

- The concentration of salt entering a POTW under this scenario is on the order of $40 \mathrm{mg} / \mathrm{L}$, far below any level of concern. 


\subsubsection{Standards for Effluent Cyanide in the State of Indiana}

An important aspect of this 'cyanide' issue is that of the low level regulatory limits imposed by IDEM relative to effluent wastewater flows. The regulatory limit for the Great Lakes Region, calculated using the Great Lake Basin Methodologies, as amenable cyanide is as follows:

- Acute aquatic life-22 $\mathbf{\mu g} / \mathbf{L}$

- Chronic aquatic life $-\mathbf{5 . 2} \boldsymbol{\mu \mathrm { g } / \mathrm { L }}$

The typical regulatory NPDES limit for Non-Great Lakes Region, listed as total cyanide, is $\mathbf{2 0}$ $27 \mu \mathrm{g} / \mathrm{L}$.

Note: The $\mathrm{CN}^{-}$limits in the state of Indiana vary regionally depending upon the 'Great Lakes Drainage Basin' versus the Non- Great Lakes region, with the difference being that amenable cyanide is the designated criteria for all Great Lake regions and total cyanide is the criteria for all non-Great Lakes region.

Yet another important factor is that the recently initiated triennial review of the Indiana Water Quality Standards suggests that the State will shortly adopt a uniform standard for stipulating 'total' cyanide throughout the state, rather than using 'amenable' in the Great Lakes region and 'total' everywhere else. The reason that this is important is because the 'amenable' test will not pick up the complexed cyanides (i.e., the INDOT anti-caking agent) but total cyanide will detect and include these complexed materials, such that their presence would impose a potential regulatory problem. As demonstrated with the preceding calculations, it would certainly appear (at least for the time period covering truck washing events) that without appropriate dilution, the effluent cyanide levels could possibly violate these aforementioned regulatory requirements, thus posing a problem for the treatment plants. 


\subsection{RESEARCH OBJECTIVES}

This research effort focuses primarily on studying the impacts of toxicity of the deicing salt wastewater generated during the washing and cleaning operations. The objective is to generate data that would help INDOT and POTWs to decide on their options as far as treatment of the salt wash wastewater is concerned. As stabilization of organic matter and removal of colloidal substances are two of the most important parameters to be considered in the treatment of wastewater, COD, OUR and Turbidity were used as the testing parameters for analyzing the efficiency of microorganisms in treating wastewater under saline conditions. Preliminary assessment on the gravity of the cyanide problem was also performed. Total and amenable cyanide levels were tested for Lafayette and West Lafayette road salts. 


\section{INTRODUCTION}

\subsection{THEORETICAL BACKGROUND}

Highway anti-icing is the snow and ice control practice of preventing the formation or development of bonded snow and ice by timely applications of chemical freezing-point depressant. In 1991, it was estimated that highway agencies in the USA spend about $\$ 1.5$ billion yearly on snow and ice control programs with approximately $15 \%$ being spent on deicing chemicals. Sodium Chloride $(\mathrm{NaCl})$ is the most commonly used chemical deicer applied at a rate of 10 million tons per year nation wide and an approximate price of $15 \$$ - 40\$ per ton. Other deicing chemicals include calcium magnesium acetate (CMA) produced from glacial acetic acid and dolomitic lime but the use of CMA in deicing applications is limited due to the high cost of CMA priced at \$204 - \$328 per ton (Transportation Research Board, 1997).

Other deicing agents include: Calcium chloride, Magnesium chloride, Potassium acetate, Potassium formate, Urea, Ethylene glycol, Propylene glycol, Isopropyl glycol and Methyl alcohol. (Minsk, 1998)

Deicing agents are applied to pavement for three main reasons: Melting (deicing) already formed ice on pavements, preventing the formation of ice on pavements (anti-icing), and preventing the buildup of compacted snow by the action of traffic. These agents melt ice by depressing the freezing point of water and forming an eutectic mixture. A eutectic mixture is a mixture of two or more substances with a melting point lower than that for any other mixture of the same substances. In the case of salt and water, the eutectic point is $-21.12^{\circ} \mathrm{C}$ or $-6.016^{\circ} \mathrm{F}$ in a solution of $23.31 \%$ salt. Figure 2.1 below shows the phase diagram of sodium chloride solution. 


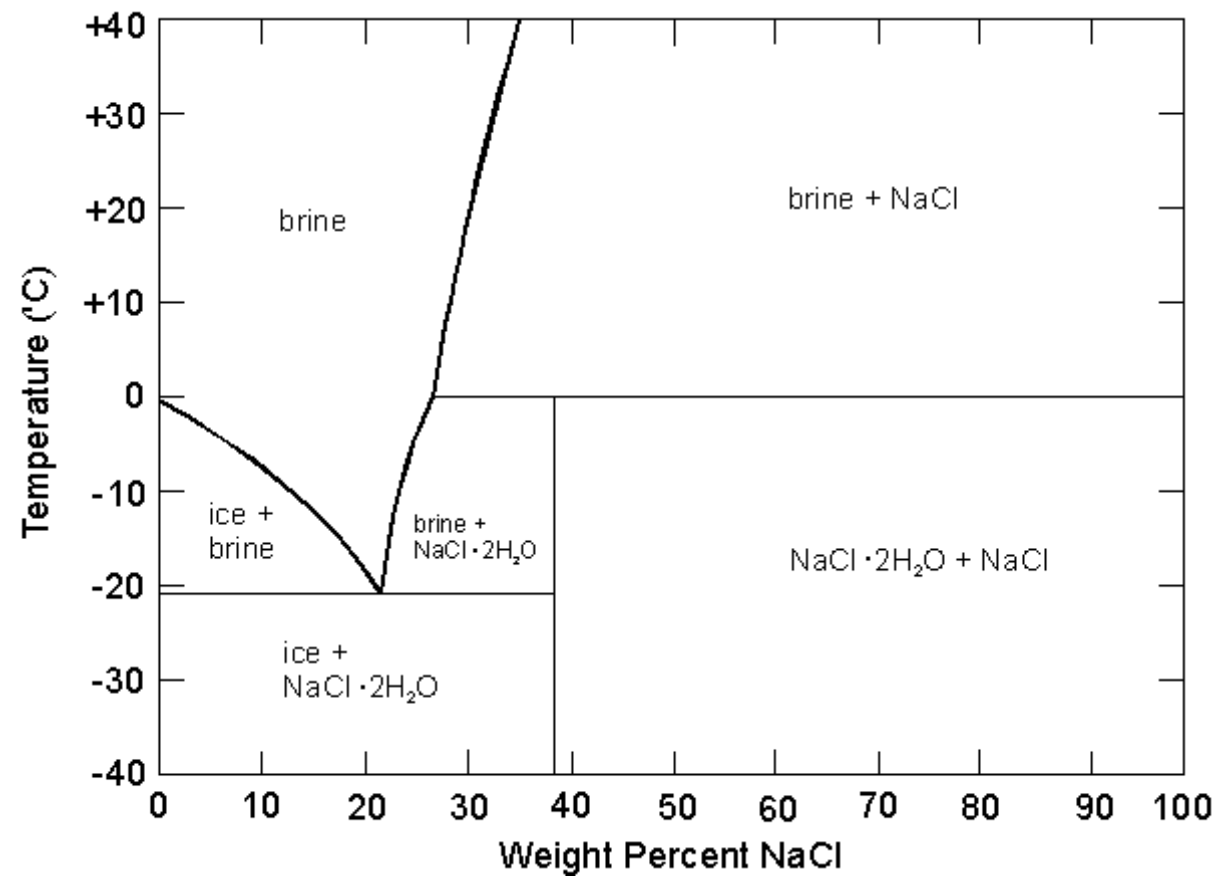

Figure 2.1 - Phase diagram of sodium chloride (Source: http://antoine.frostburg.edu/chem/senese/101/solutions/faq/)

Deicing salt is usually applied in two patterns depending on the atmospheric temperature, at air temperature of $20^{\circ} \mathrm{F}$ or higher, straight salt is applied in narrow lines on highways and pavements, producing concentrated brines that flow under the formed ice in order to break the bond between pavement and ice, in lower temperatures salt is usually prewet at the spinner using $8-10$ gallons per ton of $28 \%$ magnesium/calcium chloride solution assuming a more efficient adhesion to the pavement and faster action of wetted salt compared to that of a dry salt (HITEC, 1999). Salt is generally applied after a snowstorm event or even slightly ahead of the predicted storm incident to prevent the development of slippery conditions.

In 1991, Indiana was reported to have an average salt annual loading of 9.0 tons/lane-mile compared to the Great Lakes region average salt annual loading of 9.36 tons/lane-mile (Transportation Research Board, 1991). A more recent figured reported INDOT's average salt loading of 250 pounds /lane-mile (HITEC, 1999). 
Anti caking agents are added to deicing salt to prevent caking, lumping or agglomeration during storage or application with cyanide complexes, such as: Ferric/Ferrocyanide, AKA Prussian Blue, $\mathrm{Fe}_{4}\left(\mathrm{Fe}(\mathrm{CN})_{6}\right)_{3}$ being the most widely used for deicing purposes. Other anti caking agents include: Sodium ferrocyanide, Calcium phosphates, Magnesium phosphates, Calcium and Magnesium silicates, ...etc. However, these agents are not utilized generally due to their high cost compared to that of Ferric/Ferrocyanide.

After salt application, INDOT salt hoppers and spreader trucks are stored in truck washing facilities where they are washed simply by garden hoses and with resulting wash water high in salt content, grease, sand and other trace elements being either reused for further deicing after volume reduction or discharged into local sewer system and ultimately to POTWs.

Currently, most Indiana's POTWs will not allow the discharge of the resulting wash water into their facilities due to their concern about the possible inhibitory action of salinity on the performance of the facility and the quality requirements for their final effluent.

Studies by others addressed the performance of activated sludge processes in response to the effect of saline shock loads. Some studies showed that up to a salt concentration of $3 \%$ no inhibitory effect was noticed on the performance of aerobic activated sludge (Hamoda et al., 1991). In a different study, the author suggested that high concentrations of inorganic salts are not toxic in the conventional sense, but exhibit a decrease in the biological kinetic rate, however, he recommended that biological processes can be successfully operating at higher salt concentrations up to $5 \%$ salt by weight with the only concern being the effluent elevated suspended solids level. (Milenko, 1993). Some other researchers suggested that a shock load of $0.5-5 \%$ will reduce the effectiveness of the biological processes in wastewater treatment plants, with rapid shifts in salt concentration causing more problems than gradual shifts. Tolerance limits of salinity variations vary greatly for the organisms found in the sludge (Salvadó et. al, 2001).

Other studies suggested an increase on the specific oxygen uptake rate with a salt concentration up to $3 \%$. The same studies, however, showed that the increase in salinity levels has adversely affected 
the Specific Ammonia Uptake Rate (SAUR) and Specific Nitrate Uptake Rate (SNUR). The study suggested, though, that the impact of chloride shocks was more obvious on nitrifiers compared to denitrifiers. However, after a recovery period, bother nitrifiers and denitrifiers were able to recover their original SAUR and SNUR rates prior to the shock. (Panswad et al., 1991).

Biosensors are defined as the sensors that allow the measurement and interpretation of the biological response of activated sludge to a known disturbance. (Petersen et. Al, 2002) Respirometry, a popular biosensor, has a well established history of toxicity online monitoring on treatment plant facilities by studying characteristics of wastewater and activated sludge biodegradation kinetics. By Respirometry we generally mean the measurement and interpretation of the biological oxygen consumption rate under well-defined experimental conditions to monitor, model and control activated sludge process (Figure 2.2) (Vanrolleghem, 2002).

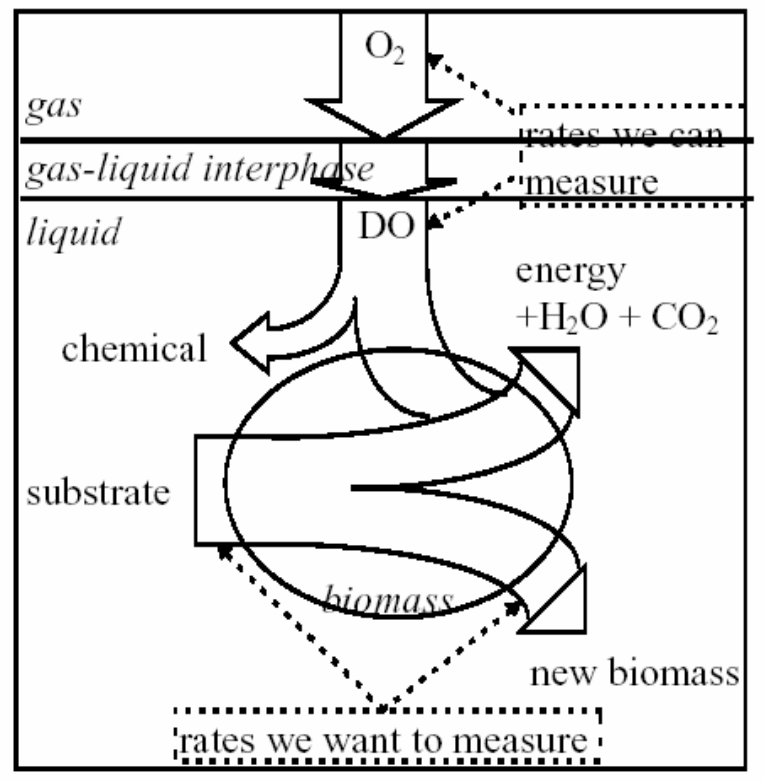

Figure 2.2 - Relationship respiration, substrate utilization and growth.

(Source: Vanrolleghem, 2002)

By measuring oxygen consumption continuously over time, respirometry can be used for assessment and evaluation of a wide range of applications including: biodegradation of specific chemicals, treatability of organic industrial wastes, the effect of known amounts of toxic compounds on the oxygen uptake rate of microorganisms, the concentration in which a pollutant inhibits biological 
degradation, the oxygen requirement for essentially complete oxidation of biologically oxidizable matter. (Standard Methods, 1995).

Three different respiration rates can be identified in respirometric studies: Endogenous respiration rate, which is the oxygen consumption rate in the absence of substrate from external sources. Actual respiration rate, which is defined as the oxygen consumption rate in the presence of a continuous input of substrate in the influent resulting in a higher respiration rate associated with a net growth in the biomass and finally, Maximum respiration rate, which approximates the maximum oxygen uptake under high biodegradable matter concentration and maximum biomass growth. Endogenous respiration rate measures only the death-regeneration of the microbial culture on the other hand, Actual respiration rate, measures the biodegradable matter in the sample that in turns result from: input from the influent, loss via effluent and biodegradation. Maximum respiration rate is considered practically independent of substrate concentration and therefore, indicative of the biomass concentration.

Respirometers are classified into eight basic principles according to the following two criteria:

1. The phase where oxygen concentration is measured (gas vs. liquid).

2. The input and output of liquid and gas (Flowing vs. static).

Different measuring principles based on this classification are summarized in the following table: 
Table 2.1- 8 Basic respirometers classification (Source: Vanrolleghem, 2002)

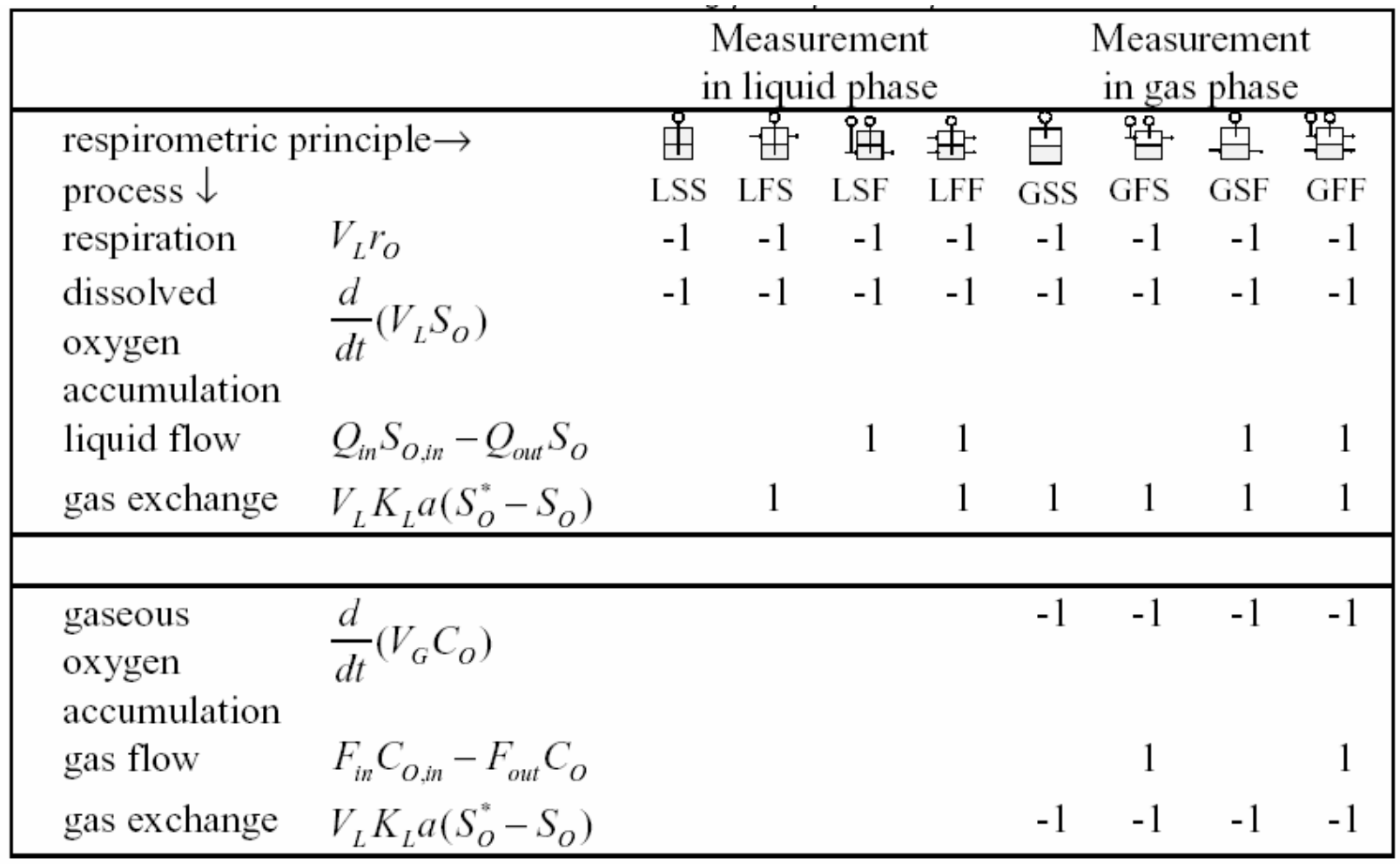

The table compares the different respirometer classes along with their mass balance terms and respirometric principles. The mass balances for each principle are formed by multiplying the mathematical terms with the coefficients in the column of the appropriate principle. The sum of all terms must equal zero.

A different classification classifies respirometers into four principle types, that are:

1. Manometric respirometers: Oxygen consumption is measured by the change in pressure of the gas phase. Example of manometric respirometers is: Warburg respirometers.

2. Volumetric respirometers: Oxygen consumption is measured by the incremental changes in gas volume while maintaining a constant pressure at the time of reading. Example of volumetric respirometers is: Sapromat respirometers.

3. Electrolytic respirometers: these respirometers monitor the amount of oxygen produced by electrolysis of water to maintain a constant oxygen pressure within the reaction vessel.

4. Direct-Input respirometers: The oxygen is delivered to the sample from a pure oxygen supply through metering on demand as detected by minute pressure difference. 
Organic substances, substances with toxic threshold and inorganic salts can exert a partial or complete inhibition on biological operations. This inhibition results from either the interference with osmotic balance or the interference with the enzyme system. This concentration of the toxic substances is also affected with other different factors like those related to the nature of the organism, food levels, temperature and $\mathrm{pH}$. Some organisms are capable of acclaimizing it self with certain levels of toxicity by some biological activities or by the selective growth within the culture of a subset of organisms that is capable of metabolism in the presence of the substance at this toxic level. (Ros, 1993).

It is suggested that by mixing, the inhibitory effect of some substances can be minimized since the influence is diluted by the aeration tank contents and the microorganisms are only subjected with the effluent concentration which is likely to be below the threshold limit of this substance.

\subsection{Previous Research ACtivities}

In the previous phases of this project, work conducted by Sharma and Anameish examined the effect of varying salt concentrations on the biological process in an activated sludge facility with means of COD measurements and Turbidity. It was generally concluded that within the range of salt concentration between $0-1500 \mathrm{mg} / \mathrm{L}$ for COD and $0-10,000 \mathrm{mg} / \mathrm{L}$ for turbidity no negative effect was found on the performance of the activated sludge kinetics. It was suggested, however, that further work takes place to examine the effect of salt loads with concentrations beyond $2,000 \mathrm{mg} / \mathrm{L}$.

\subsection{Proposed ReSEARCH APPROACH}

The impact assessment on the biological performance of activated sludge is to be run on a 8-reactor, temperature control, computer-interfaced, Static liquid - Flowing Gas Comput-OX Respirometer described in the following apparatus section. Salt to be added to 6 reactors in a solid or a solution form depending on the desired final concentration with the remaining 2 reactors used for monitoring and control. One reactor to have a blank DI water sample with an oxidizing agent like 
bleach for instrument control and the other reactor to have a zero-salt wastewater sample for comparison purposes. Magnetic stirrers are to be used to ensure proper mixing of the sample. Potassium Hydroxide $(\mathrm{KOH})$ pellets to be used for $\mathrm{CO}_{2}$ stripping. Testing temperature to be controlled at $20^{\circ} \mathrm{C}$ using a controlled temperature water bath. Testing period should be maintained at a minimum of 6 hours.

Taking the slope of the of total mass of oxygen delivered to the reactor in milligrams of oxygen per liter - hour as the respiration rate, the inhibitation effect $(\mathrm{I} \%)$ of the respiration rate of the biomass can be calculated as (Mrafkova et al, 2003):

$$
I=\left(1-\frac{R_{s}}{R_{c}}\right) \cdot 100
$$

where:

$\mathrm{I}=$ Inhibition Effect $(\%)$

$\mathrm{R}_{\mathrm{s}} \quad=$ Respiration rate for testing sample, $\mathrm{mg} \mathrm{O}_{2} / \mathrm{L}-\mathrm{Hr}$

$\mathrm{R}_{\mathrm{c}} \quad=$ Respiration rate for control sample, $\mathrm{mg} \mathrm{O}_{2} / \mathrm{L}-\mathrm{Hr}$

Based on the above definition, $\mathrm{IC}_{50}$ is defined as the concentration causing $50 \%$ inhibitation.

Solubility of Oxygen is affected with salt concentration, oxygen solubility at $20^{\circ} \mathrm{C}$ will vary from 9.16 $\mathrm{mg} / \mathrm{l}$ at $400 \mathrm{ppm}$ to as low as 8.97 at $2500 \mathrm{ppm}$ (Ros, 1993). 


\section{MATERIALS AND METHOdS}

\subsection{SAMpling AND Preparation}

Wastewater samples were collected from the Return Activated Sludge (RAS) pumps in West Lafayette Wastewater Treatment Plant. Influent in this facility is characterized by a low strength with a reported carbonaceous biochemical oxygen demand of $146 \mathrm{mg} / \mathrm{L}$. Average influent temperature during the study period was recorded at $15^{\circ} \mathrm{C}$.

Generally, RAS is characterized with a high biomass concentration and often a low dissolved oxygen and substrate concentration. RAS samples were stored in the cold room at $4^{\circ} \mathrm{C}$. Storage period was minimized to 48 hours and fresh samples were obtained whenever possible.

Deicing salt was obtained from two different INDOT facilities located in Lafayette and West Lafayette areas. One of the samples was characterized with clear blue color resulting from the presence of Prussian Blue (See figure 3.1 below). This sample was applied in a solid form for a final sample salt concentration as high as $10 \%$. The other sample was used in a solution form to achieve a maximum salt concentration of $4 \%$.

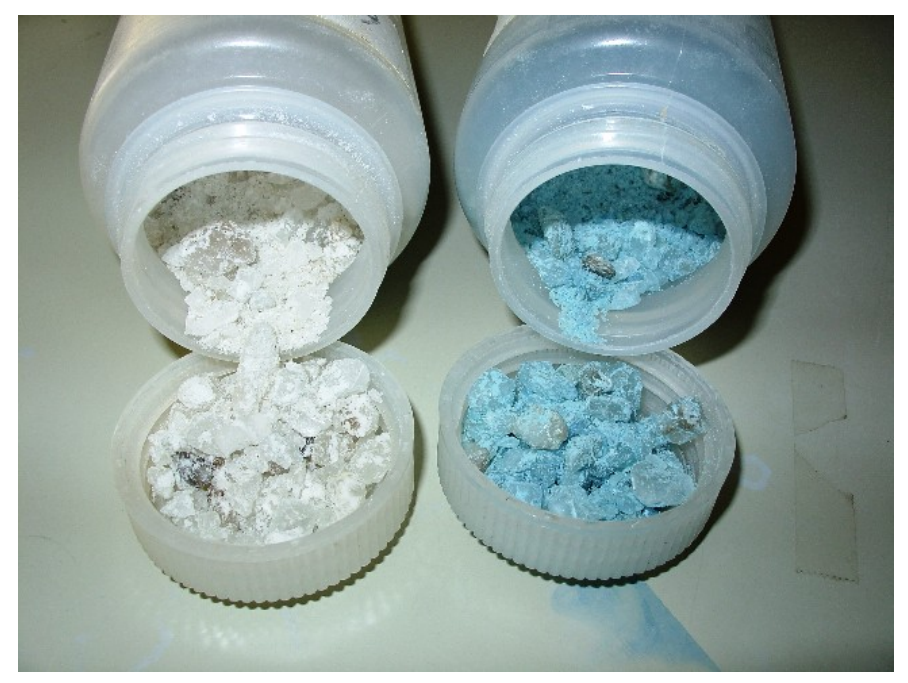

Figure 3.1 -Deicing Salt Samples 


\subsection{APPARATUS AND SYSTEM DESCRIPTION}

N-CON Comput-OX Respirometer, model WB-400, a direct-input static liquid - flowing gas respirometer, is used for the experimental measurement of the biological performance of activated sludge under variable saline brines shock loads (Figure 3.2). This 8-reactor respirometer is controlled and operated using a LabVIEW computer interface and is based on the pressure drop generated during respiration in the presence of potassium hydroxide $(\mathrm{KOH})$ pellets. As respiration takes place, oxygen becomes depleted and carbon dioxide is being generated at the same rate in the sealed atmosphere of the reactor. Potassium hydroxide pellets strips carbon dioxide in the form of potassium carbonate as in the following reaction:

$$
2 \mathrm{KOH}+\mathrm{CO}_{2} \rightarrow \mathrm{K}_{2} \mathrm{CO}_{3}+\mathrm{H}_{2} \mathrm{O}
$$

The pressure drop is then detected by a pressure sensor that in turns, deliver a signal to the computer via the input/output interface and then an oxygen pulse is delivered to the appropriate reactor. This process is recorded with a computerized data acquisition system. The test data can be exported to MS Excel for further analysis. Respiration takes place in sealed atmosphere batch reactors with a minimum detection limit of pressure drops as low as $2 \mathrm{~mm}$ of $\mathrm{H}_{2} \mathrm{O}$.

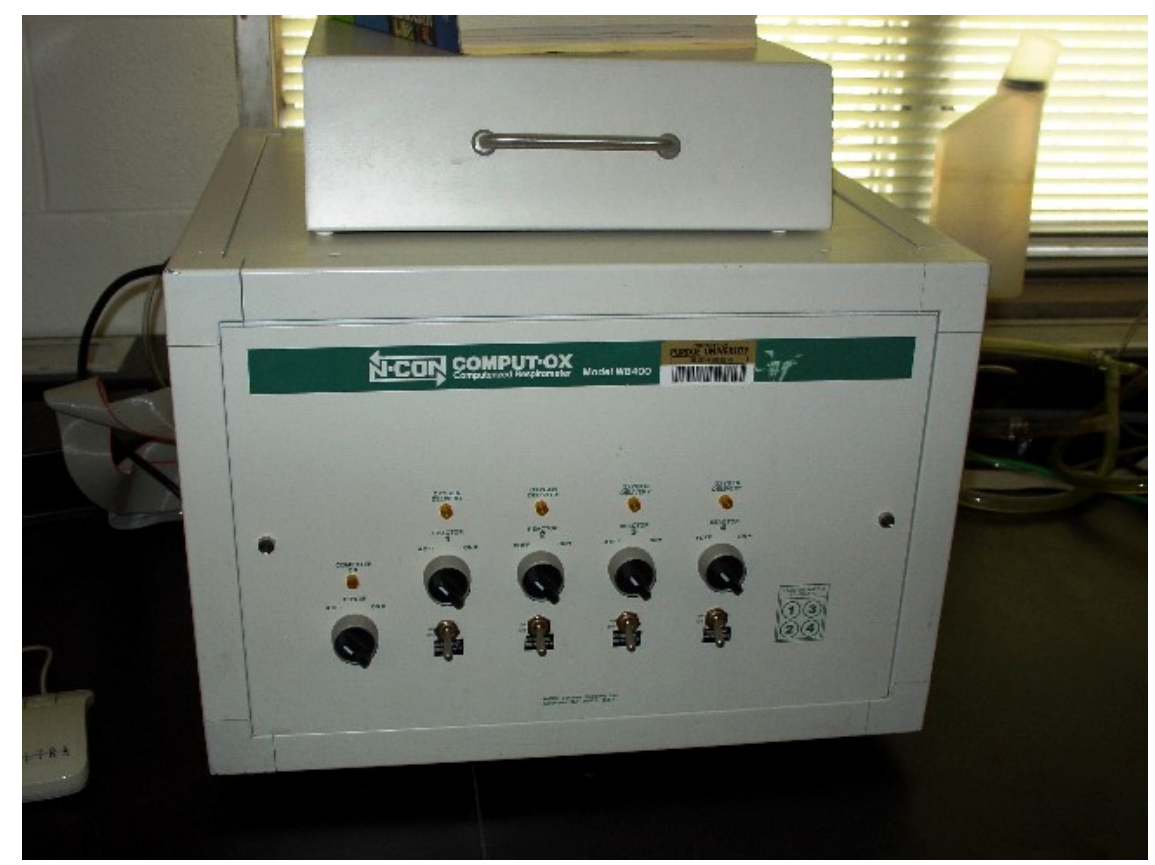

Figure 3.2 - N-CON Comput-OX WB-400 Respirometer 
Testing is to be conducted on a controlled temperature of $20^{\circ} \mathrm{C}$ using NESLAB RTE-10 Digital One refrigerated circulator. Accurate control of testing temperature is required since sudden changes in temperature during testing will interfere with testing results.

\subsection{EXPERIMENTAL SETUP}

Prior to conducting the tests, the respirometer was calibrated as outlined in N-CON's operation manual. Gas switches indicated an accuracy level ranging from 97\% - 99.9\%.

No standardized procedures are outlines for the oxygen uptake measurement techniques. Testing procedures are more manufacturer dependant. Detailed respirometer operation procedures are documented in the manufacturer's operation manual and won't be discussed under the scope of this report.

Two testing schemes were performed for the purpose of evaluation of the effect of saline shock loads on the oxygen uptake rate of activated sludge. The testing schemes were as follows:

\subsubsection{Scheme 1}

$250 \mathrm{ml}$ RAS samples were seeded with solid deicing salt characterized with the blue color resulting from Prussian Blue to achieve a final salt concentration ranging from $1 \%(10 \mathrm{~g} / \mathrm{L})$ to $10 \%(100 \mathrm{~g} / \mathrm{L})$.

Endogenous respiration rate was measured under this testing scheme, no substrate was added to the biomass and the RAS samples didn't experience any dilution. Tests were run for durations ranging from 8 hours to up to 19 hours to characterize the different phases of the oxygen uptake of the biomass.

Six test duplicates were taken for calculations and further observations with salt concentrations of: 1, 2, 4, 6, 8 and $10 \%$ by weight. 


\subsubsection{Scheme 2}

For this scheme, 250ml RAS samples were seeded with TSB (Tryptic Soy Broth) stock solution at $15 \mathrm{~g} / \mathrm{L}$ and different volumes of deicing salt stock solution (12.5\%) to achieve a final salt concentration ranging from 0 to $4 \%(40 \mathrm{~g} / \mathrm{L})$. Table 3.1 below summarizes the different dilution factors used for sample preparation for scheme 2.

Table 3.1 - Dilution Factors for Sample Preparation (Scheme 2)

\begin{tabular}{cccccccc}
\hline $\begin{array}{c}\mathbf{C}_{\text {Final }} \\
(\mathbf{\%})\end{array}$ & $\begin{array}{c}\mathbf{V}_{\text {RAS }} \\
(\mathbf{m L})\end{array}$ & $\begin{array}{c}\mathbf{V}_{\text {salt }} \\
(\mathbf{m L})\end{array}$ & $\begin{array}{c}\mathbf{V}_{\text {water }} \\
(\mathbf{m L})\end{array}$ & $\begin{array}{c}\mathbf{V}_{\text {TSB }} \\
(\mathbf{m L})\end{array}$ & $\begin{array}{c}\mathbf{C}_{\text {TSB }} \\
(\mathbf{m g} / \mathbf{L})\end{array}$ & $\begin{array}{c}\mathbf{C O D}_{\text {TSB }} \\
(\mathbf{m g} / \mathbf{L})\end{array}$ & $\begin{array}{c}\mathbf{V}_{\text {Total }} \\
(\mathbf{m g} / \mathbf{L})\end{array}$ \\
\hline 0.00 & 250 & 0.0 & 125.0 & 4.6 & 180.5 & 100.0 & 379.6 \\
0.50 & 250 & 15.2 & 109.8 & 4.6 & 180.5 & 100.0 & 379.6 \\
1.00 & 250 & 30.4 & 94.6 & 4.6 & 180.5 & 100.0 & 379.6 \\
1.50 & 250 & 45.5 & 79.5 & 4.6 & 180.5 & 100.0 & 379.6 \\
2.00 & 250 & 60.7 & 64.3 & 4.6 & 180.5 & 100.0 & 379.6 \\
3.00 & 250 & 91.1 & 33.9 & 4.6 & 180.5 & 100.0 & 379.6 \\
4.00 & 250 & 121.5 & 3.5 & 4.6 & 180.5 & 100.0 & 379.6 \\
\hline
\end{tabular}

Tryptic Soy Broth (TSB) is a general purpose highly nutritious medium that is used for the cultivation of microorganisms. Testing reactors were seeded with TSB to add an additional $100 \mathrm{~g} / \mathrm{L}$ of COD to the testing samples and thus, measuring the Actual respiration rate. $1 \mathrm{~g}$ of TSB is equivalent to $0.554 \mathrm{~g}$ of COD.

Tests were run for durations ranging from 8 hours to up to 40 hours to characterize the different phases of the oxygen uptake of the biomass.

Six test duplicates were taken for calculations and further observations with salt concentrations of: $0.5,1,1.5,2,3$ and $4 \%$ by weight.

\subsection{WASTEWATER SAMPLE AND ITS CHARACTERISTICS}

Wastewater samples were obtained from the recycled activated sludge line of the activated sludge system at the West Lafayette Waste Water Treatment plant (WLWWTP). It was 
appropriately diluted with tap water to get a representative mixed liquor suspended solids (MLSS) concentration in the reactor (around $3000 \mathrm{mg} / \mathrm{L}$ ). The wastewater at the WLWWTP is a low strength wastewater with an average influent carbonaceous biochemical oxygen demand of 146 mg/L (Source: West Lafayette Wastewater Treatment Plant).

Air was bubbled through the samples continuously to keep the system aerobic and to ensure healthy environment for the microbes. Samples stored for more than 2 days were dosed with glucose, so as to maintain a supply of food mass for the microbes. All experiments were conducted at room temperature $\left(20-22^{\circ} \mathrm{C}\right)$.

\subsubsection{Chemical Oxygen Demand}

The chemical oxygen demand (COD) is used as a measure of the oxygen equivalent of the organic matter content of a sample that is susceptible to oxidation by a strong chemical oxidant (Standard Methods, 1989). This test allows measurement of a wastewater in terms of the total quantity of oxygen required for oxidation to carbon dioxide and water. Measured wastewater sample is heated with a known amount of potassium dichromate- sulfuric acid solution. Some of the dichromate is consumed in the oxidation of organic wastes.

\section{EXPERIMENTAL SET-UP AND PROCEDURE}

The procedure followed for the COD measurements was as specified in the Standard Methods. A series of standard solutions that cover the expected range of sample concentrations was prepared by diluting appropriate volumes of the potassium hydrogen phthalate stock solution $(0.85034$ gms in 1 liter $=1000 \mathrm{mg} / \mathrm{L}$ ). Table 3-2 shows the dilution series used. Figure 3-3 shows the calibration curve used for measuring the COD of wastewater samples. 
Table 3-2: Dilution Series for COD Standards

\begin{tabular}{|c|c|c|}
\hline Concentration (mg/L) & Stock Solution (mg/L) & Final Volume (m) \\
\hline 0 & 0 & 100 \\
\hline 10 & 1 & 100 \\
\hline 25 & 2.5 & 100 \\
\hline 50 & 5 & 100 \\
\hline 80 & 8 & 100 \\
\hline 100 & 10 & 100 \\
\hline 150 & 15 & 100 \\
\hline
\end{tabular}

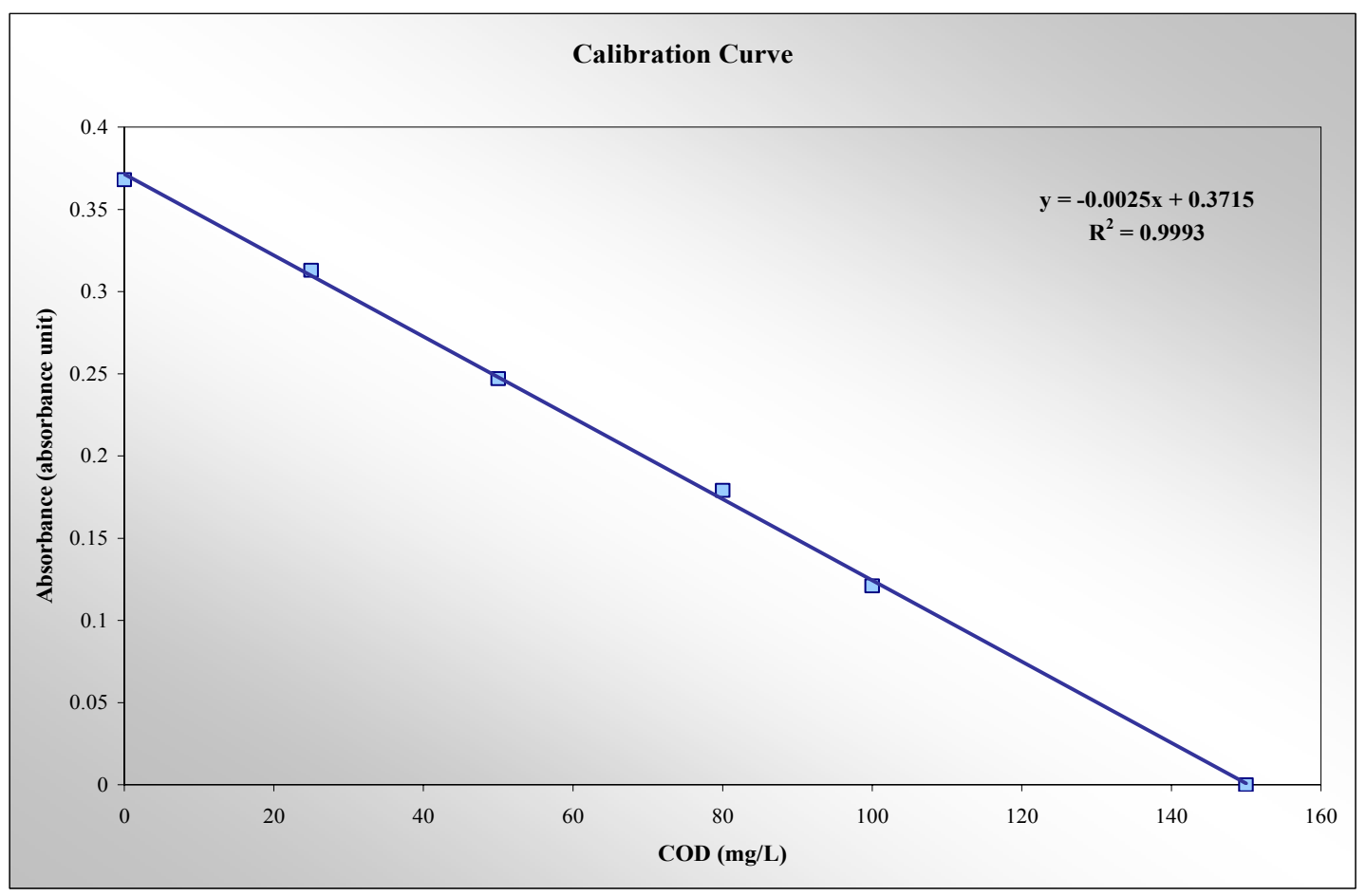

Figure 3-3: Calibration Curve for COD Stabilization

Four bench-scale, completely mixed aerobic reactors containing active biomass were set up in parallel. Total volume in each reactor was $500 \mathrm{ml}$. Filtered, compressed air was bubbled through porous ceramic diffusers in the reactors and the contents were continuously stirred to maintain an aerobic environment and to ensure thorough mixing. Varying levels of salt concentration (West Lafayette road salt) - 0 (control), 500, 1000 and $1500 \mathrm{mg} / \mathrm{L}$ were instantly injected into the reactors in the form of a pulse, thereby shock loading the biomass therein. As the wastewater 
had low background COD, it was increased using Tryptic Soy Broth (TSB) so as to get appreciable COD readings.

An aliquot of the samples was taken from each reactor every 30 minutes for duration of 150 minutes and filtered using a $0.45 \mu \mathrm{m}$ syringe filter. $2.5 \mathrm{ml}$ of the filtered sample was added to the COD vials provided by Bioscience Inc. The COD vials are sealed $10 \mathrm{ml}$ borosilicate glass vessels which contain premixed COD reagents as prescribed in the Standard Methods. These vials containing the samples were digested for a period of $2 \mathrm{hrs}$ using a heater that had been preheated to $150^{\circ} \mathrm{C}$ for 30 minutes. The 2-hr oxidation period is standard practice and is sufficient for complete oxidation of most compounds.

After digestion, the vials were shaken to completely mix the contents and were then allowed to cool down to the room temperature before taking the measurements. After digestion, precaution was taken that the vials are stored in a cool dark place to avoid exposure to sunlight because in the presence of light the dichromate ion decomposes to form the chromate ion and this could lead to erroneous results.

COD standards using potassium hydrogen phthalate were also conducted each time the experiment was run on actual wastewater sample so as to maintain consistency and to ensure accurate readings.

For samples in the range of $0-150 \mathrm{mg} / \mathrm{L}$, the COD is determined using a spectrophotometer at $440 \mathrm{~nm}$ by measuring the decrease in concentration of the $\mathrm{Cr}$ (VI) ion. The path length of the tubes is $1.40 \mathrm{~cm}$. In this study, a double beam spectrophotometer provided by the Shimadzu Company was used for the COD measurements. It was set in the photometric mode. Baseline correction was performed each time when the spectrophotometer was used to ensure proper calibration. As the low range COD test method measures the decrease of Cr (VI) ion, the highest standard i.e. $150 \mathrm{mg} / \mathrm{L}$ COD was used to set the spectrophotometer to zero absorbance at $440 \mathrm{~nm}$. This is so because highest COD would have the lowest Cr (VI). An aliquot was taken from the cool digested COD vials and poured into clear four sided glass disposable cuvette to take the measurements in the spectrophotometer. 
During the initial course of the experiments, difficulties were faced in terms of getting stable absorbance readings using the spectrophotometer. Research into the working of the doublebeam spectrophotometer and its use for measuring low range CODs showed that for the 0-150 $\mathrm{mg} / \mathrm{L}$, as the COD is measured in terms of disappearance of the dichromate, the $150 \mathrm{mg} / \mathrm{L} \mathrm{blank}$ sample should be kept in the reference beam of the spectrophotometer and not deionized water as this would give unstable readings. After applying this correction to the usual method, stable readings were observed. Calibration standards conducted with known COD concentrations using potassium hydrogen phthalate, gave an $\mathrm{R}^{2}$ value of 0.999 , indicating that the spectrophotometer was giving good and reliable results. The experiments were repeated a few times to ensure that the results are reproducible.

\subsubsection{Turbidity}

Turbidity is a test used to indicate the quality of waste discharges and natural waters with respect to colloidal and residual suspended matter. It is a measure of the light-transmitting properties of water. The measurement is based on comparison of the intensity of light scattered by a sample as compared to the light scattered by a reference suspension under the same conditions. Colloidal matter scatters or absorbs light and thus prevents its transmission (Metcalf and Eddy, 1991).

\section{EXPERIMENTAL SET-UP AND PROCEDURE}

Four reactors were run in parallel at a time for taking the turbidity measurements. They were stirred continuously at low speed that is optimum for flocculation. Varying levels of West Lafayette's road salt concentrations were added and its effect studied: 0 (control), 1000, 2000, 3000,6000 and, 10,000 mg/L. Samples were collected every 1 hour for a period of 3 hours for studying the effect on turbidity with time. Samples were allowed to settle in $50 \mathrm{~mL}$ volumetric cylinder for 30-45 minutes. The supernatant was pipetted out and the turbidity was measured in 
Nephelometric Turbidity Units (NTU) using the Hach Turbidimeter. The turbidimeter was checked for calibration using the secondary standards as described in the Standard Methods.

\subsubsection{Cyanide}

\section{EXPERIMENTAL SET-UP AND PROCEDURE}

In order to find the actual cyanide levels that can be expected to reach the wastewater treatment plants, testing for total and amenable cyanide was performed on Lafayette (appears blue in color indicating presence of large quantities of Prussian Blue i.e. ferric ferrocyanide) and West Lafayette road salts. Tests were performed by the Heritage Laboratories, Indianapolis. The concentration of road salt in the samples given for testing was $100 \mathrm{gms} / \mathrm{L}$ tap water.

To study the effect of light, one of the samples was subjected to UV radiation so as to see if any measurable difference in readings was observed as compared to the samples that were not exposed to light. Samples were continuously stirred and subjected to UV beam. They were kept in flat open trays to ensure that maximum surface area is in contact with the beam and that it is evenly distributed within the sample.

The transmittance of these samples was measured using the spectrophotometer. The time required for exposure under UV beam for each of these samples was determined using the following equations:

$$
I_{a v g}=I_{o}(1-\exp (-\alpha H) / \alpha H
$$

(Equation 1)

where;

$\mathrm{I}_{\text {avg }}=$ average $\mathrm{UV}$ dose $\left(\mathrm{mW} / \mathrm{cm}^{2}\right)$

$\mathrm{I}_{\mathrm{o}}=0.1249 \mathrm{~mW} / \mathrm{cm}^{2}$

$\mathrm{T}=$ Transmittance

$\alpha=-\ln \mathrm{T}$

$\mathrm{H}=3.3 \mathrm{~cm}$ 
A high intensity dose of $100 \mathrm{~mJ} / \mathrm{cm}^{2}$ was selected, to expose the sample to strong radiation.

Table 3-3: Exposure Times for Salt Samples

\begin{tabular}{|c|c|c|c|c|}
\hline Sample & Transmittance & $\boldsymbol{\alpha}$ & $\mathbf{I}_{\text {avg }}\left(\mathbf{m W} / \mathbf{c m}^{\mathbf{2}}\right)$ & Time \\
\hline Lafayette & 0.564 & 0.572 & 0.056 & $29 \mathrm{~min} 40 \mathrm{sec}$ \\
\hline West Lafayette & 0.813 & 0.207 & 0.090 & $18 \mathrm{~min} 26 \mathrm{sec}$ \\
\hline
\end{tabular}

The mass of inerts in each of the samples given for testing was also measured. 


\section{RESULTS AND DISCUSSIONS}

\subsection{Respirometry}

By varying the salt concentrations in the testing samples, different oxygen uptake were observed corresponding to the different salt loads. Measured oxygen uptake reflects the oxygen used for synthesis of the present biomass in addition to the endogenous respiration of the biomass.

A respirogram relates the oxygen uptake by microorganisms to elapsed time was produced for each reactor per testing time (see Figure 4.1 below). Complete set of respirograms are included in the appendix.

This oxygen uptake kinetics can be formulated in accordance with non-inhibitory Monod kinetics, based on first order Michaelis-Menten model for kinetic properties. Monod kinetics is formulated as follows: (Ros, 1993)

$$
-\frac{1}{V S S} \cdot \frac{d S}{d t}=\frac{\mu_{m}}{Y} \cdot \frac{S}{K_{s}+S}
$$

Where:

$\mathrm{S} \quad=$ Substrate Concentration

$\mu_{\mathrm{m}} \quad=$ Maximum specific growth rate of microorganisms

VSS $=$ Volatile suspended solids, said to be proportional to cell biomass

$\mathrm{K}_{\mathrm{s}} \quad=$ Monod's constant, equal to substrate concentration at one-half the maximum rate

$\mathrm{Y} \quad=$ Biomass yield coefficient

For the presence of substances that inhibits growth as well as those stimulating the growth, the kinetics can be modeled using Haldane kinetics, as follows:

$$
-\frac{1}{V S S} \cdot \frac{d S}{d t}=\frac{\mu_{m}}{Y} \cdot \frac{S}{K_{s}+S+S^{2} / K_{i}}
$$

The inhibitory nature of the wastes to the biological kinetic is accounted for by adding and additional constant termed, $\mathrm{Ki}$, that is called inhibitory constant. By examining the kinetics relationship between $\mu$ vs. S, the waste can be characterized by either being non-inhibitory or inhibitory. (Rozich, Gaudy, 1992) 
The respirogram is characterized with a lag period followed by an exponential growth reflected in the oxygen uptake and eventually a declining period. For the sake of analysis of the salt inhibitory action, the linear portion of the curve was considered and a minimum of 6 hours was considered for the analysis. Typical Hydraulic Retention Time (HRT) for the aeration zone can range from 6 hours to up to 30 hours which is more likely to be the duration of the salt shock load.

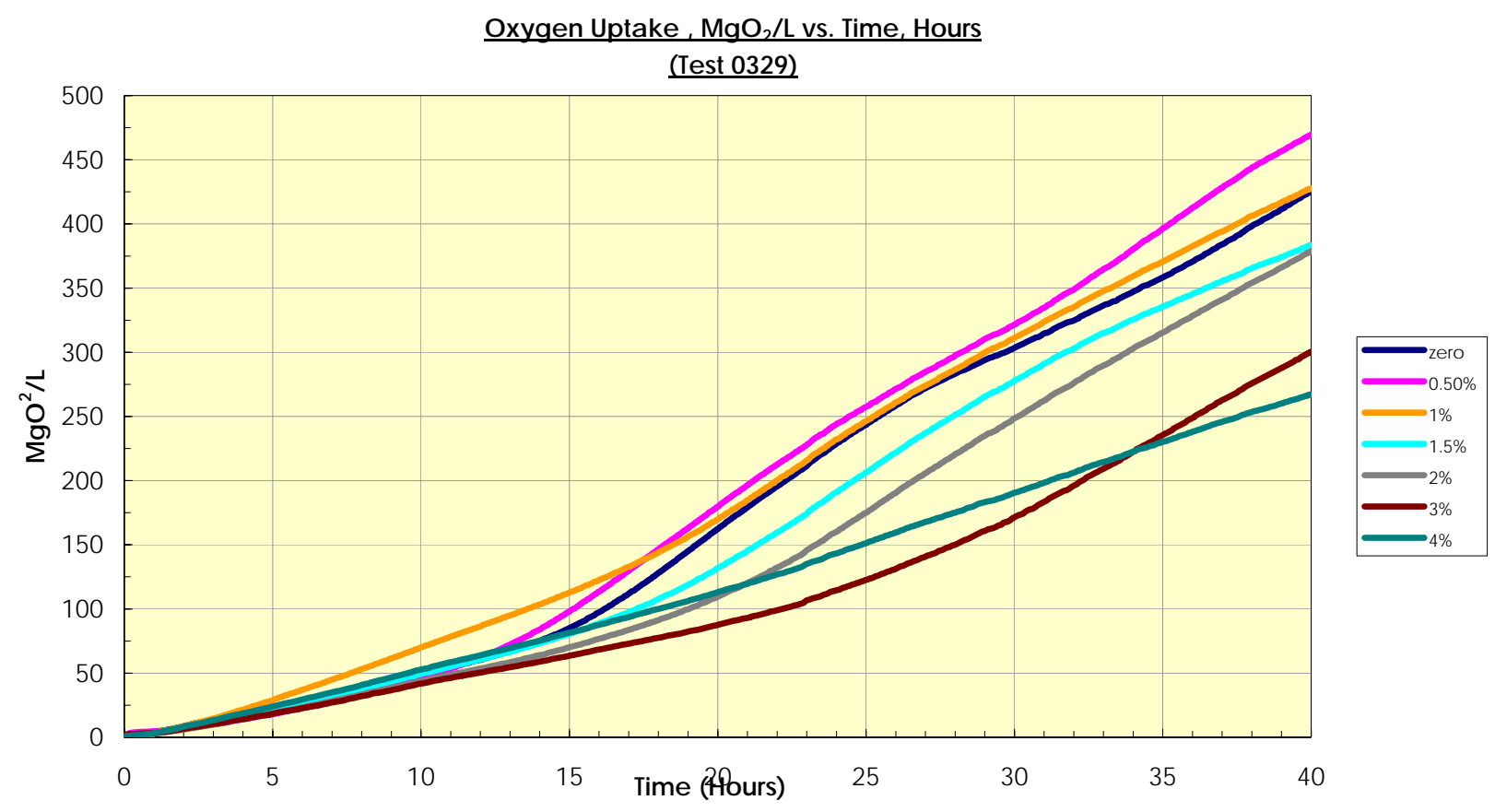

Figure 4.1 - Sample respirogram (Test 0329)

Slope of the respirogram in the linear region is denoted as the respiration rate, $\mathrm{R}_{\mathrm{s}}$ and by comparing the testing sample respiration rate to that of the control sample the inhibitory effect, I, of the different salt shock loads can be determined. Table 4.1 and Figure 4.2 below summarizes the testing results for scheme 1, error bars are indicative of the standard deviation. 
Table 4.1 - Scheme 1 Testing Results

\begin{tabular}{cccc}
\hline [Salt], $\%$ & $\begin{array}{c}\text { AVG Relative } \\
\text { Slope }\end{array}$ & $\begin{array}{c}\text { Inhibitory Effect, } \\
\mathbf{\%}\end{array}$ & STDEV \\
\hline $1 \%$ & 1.39293 & -39.293 & 0.446124 \\
$2 \%$ & 1.125788 & -12.579 & 0.137298 \\
$4 \%$ & 0.979623 & 2.0378 & 0.13029 \\
$6 \%$ & 0.649895 & 35.010 & 0.213449 \\
$8 \%$ & 0.458721 & 54.128 & 0.081933 \\
$10 \%$ & 0.460075 & 53.992 & 0.100705 \\
\hline
\end{tabular}

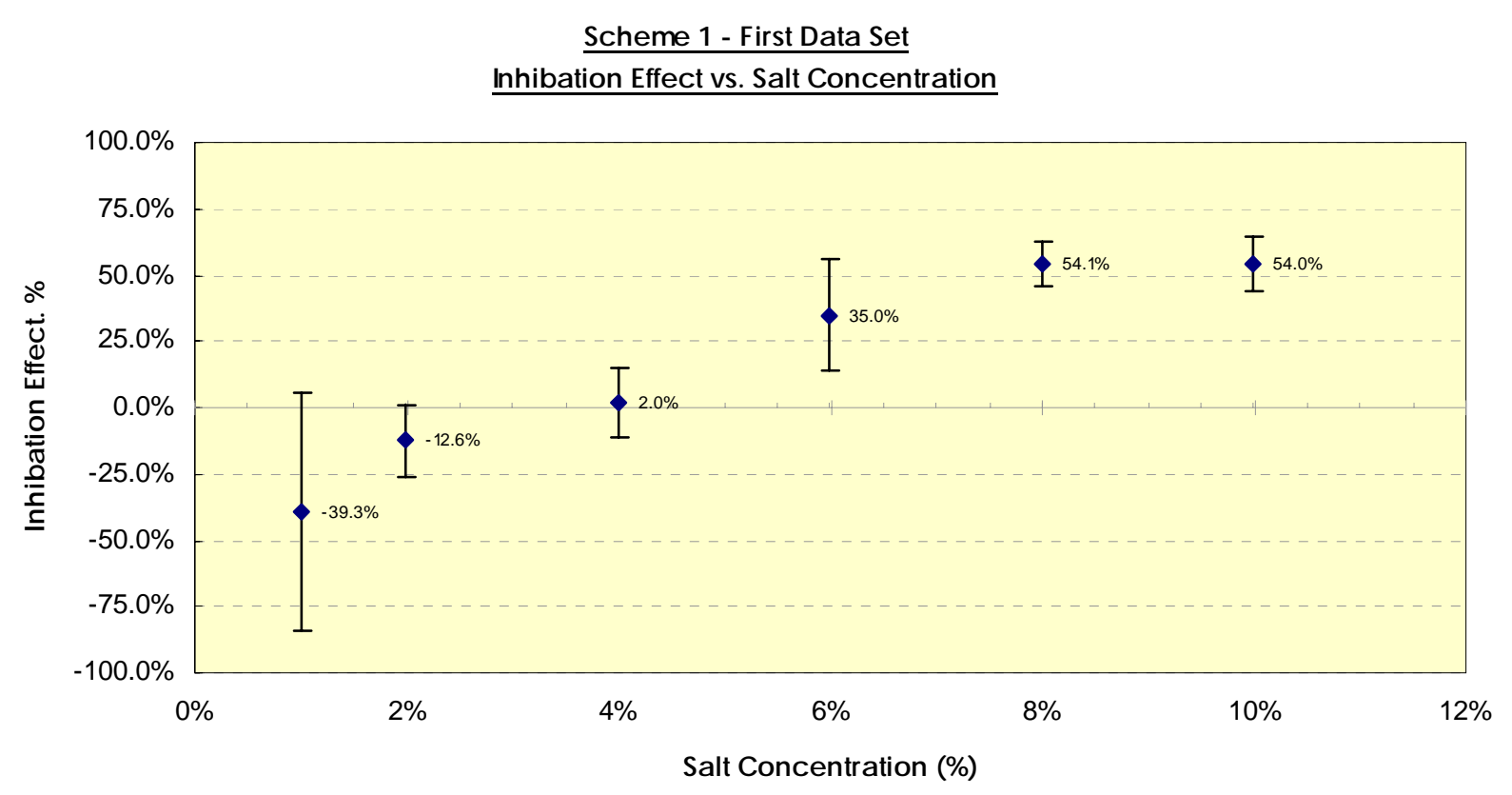

Figure 4.2 - Scheme 1 Testing Results

It can be observed that salt shock loads up to $4 \%$ resulted in a positive respiration rate reflected in negative inhibition effect. $\mathrm{IC}_{50}$ is somewhere between $6 \%$ and $8 \%$ salt.

Testing results for scheme 2 are summarized in Table 4.2 and Figure 4.3 below. 
Table 4.2 - Scheme 2 Testing Results

\begin{tabular}{cccc}
\hline [Salt], \% & $\begin{array}{c}\text { AVG Relative } \\
\text { Slope }\end{array}$ & $\begin{array}{c}\text { Inhibitory Effect, } \\
\mathbf{\%}\end{array}$ & STDEV \\
\hline $0.50 \%$ & 0.795791 & 20.4209 & 0.134685 \\
$1.00 \%$ & 1.296754 & -29.675 & 0.153882 \\
$1.50 \%$ & 0.863631 & 13.6369 & 0.164149 \\
$2 \%$ & 0.749294 & 25.0706 & 0.203476 \\
$3 \%$ & 0.767321 & 23.2679 & 0.194817 \\
\hline
\end{tabular}

Scheme 2 - Second Data Set

Inhibation Rate vs. Salt Concentration

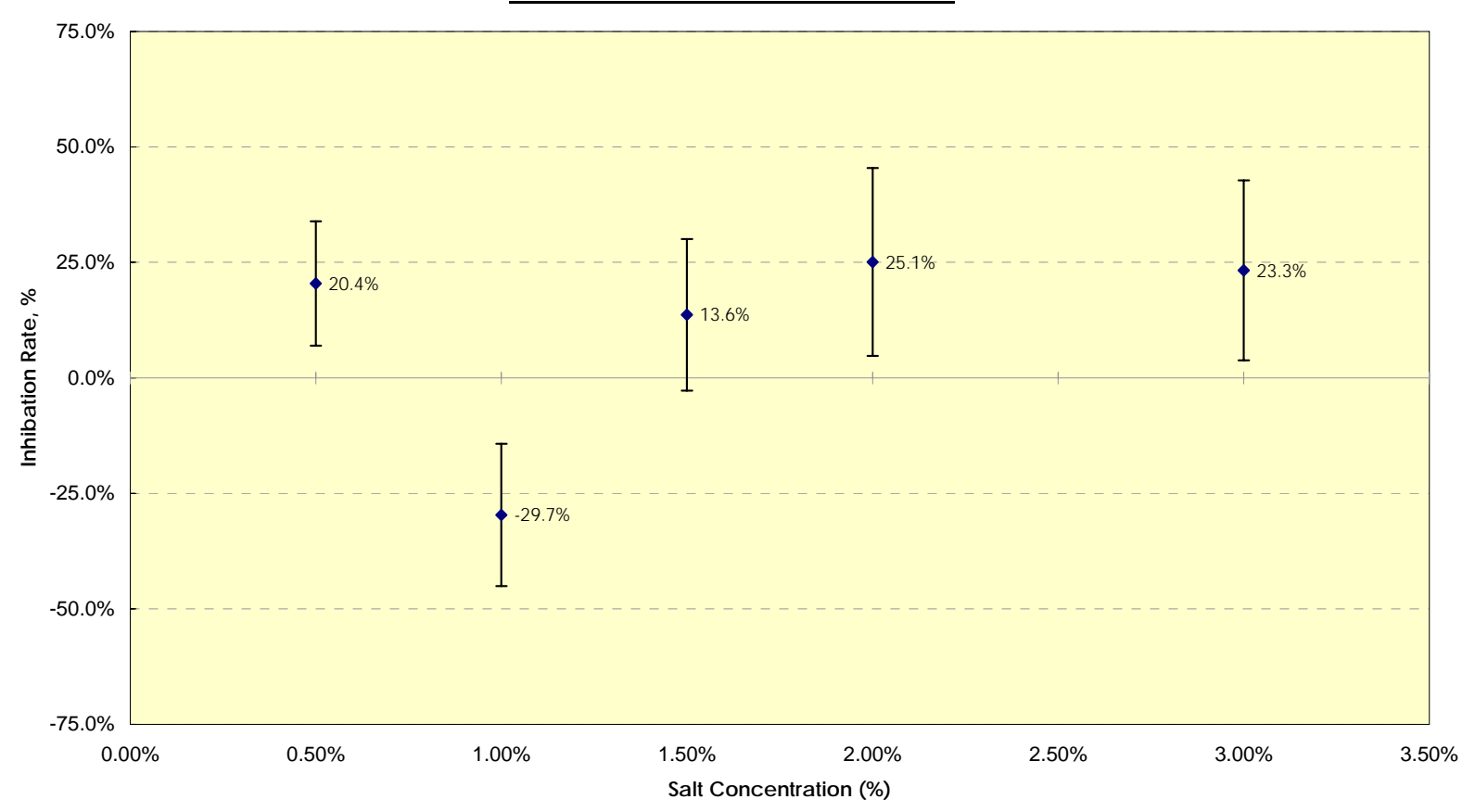

Figure 4.3 - Scheme 2 Testing Results

For this testing scheme, an inhibition of $20 \%$ was observed with a low salt concentration of $0.5 \%$ followed by an increase in oxygen uptake at a salt concentration of $1 \%$ that is somehow consistent with data obtained from the first scheme, increasing the salt concentration up to $3 \%$ resulted in inhibition of $23 \%$. 
For this testing scheme, salt stock solution at $12.5 \%$ was used rather than the solid salt form. Uncertainties associated with impurities with the solid salt can associated with the variation in testing results between scheme 1 and scheme 2 .

\subsection{COD DEPLETION RATE IMPACT RESULTS}

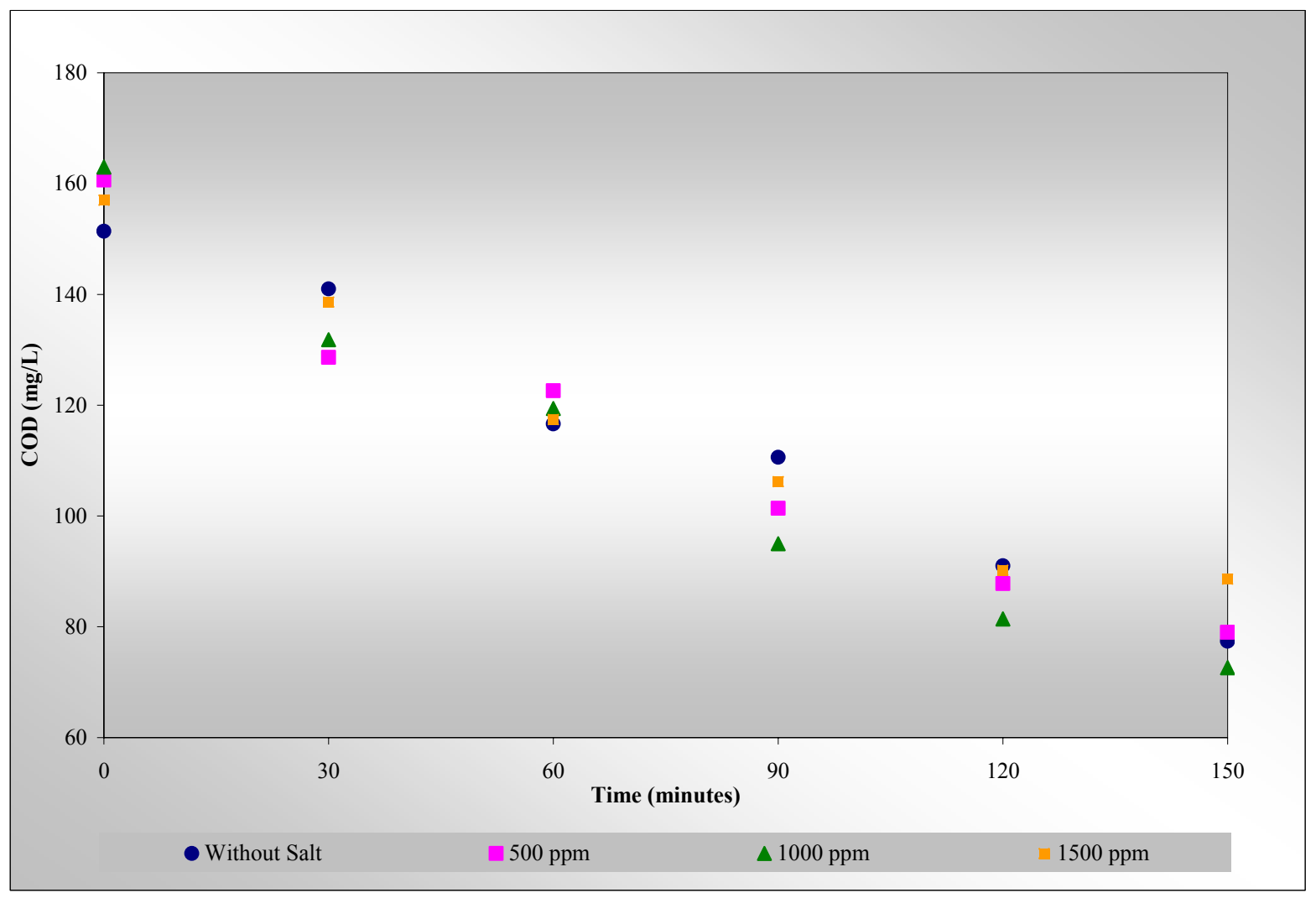

Figure 4-4: COD Stabilization - Experimental Results 


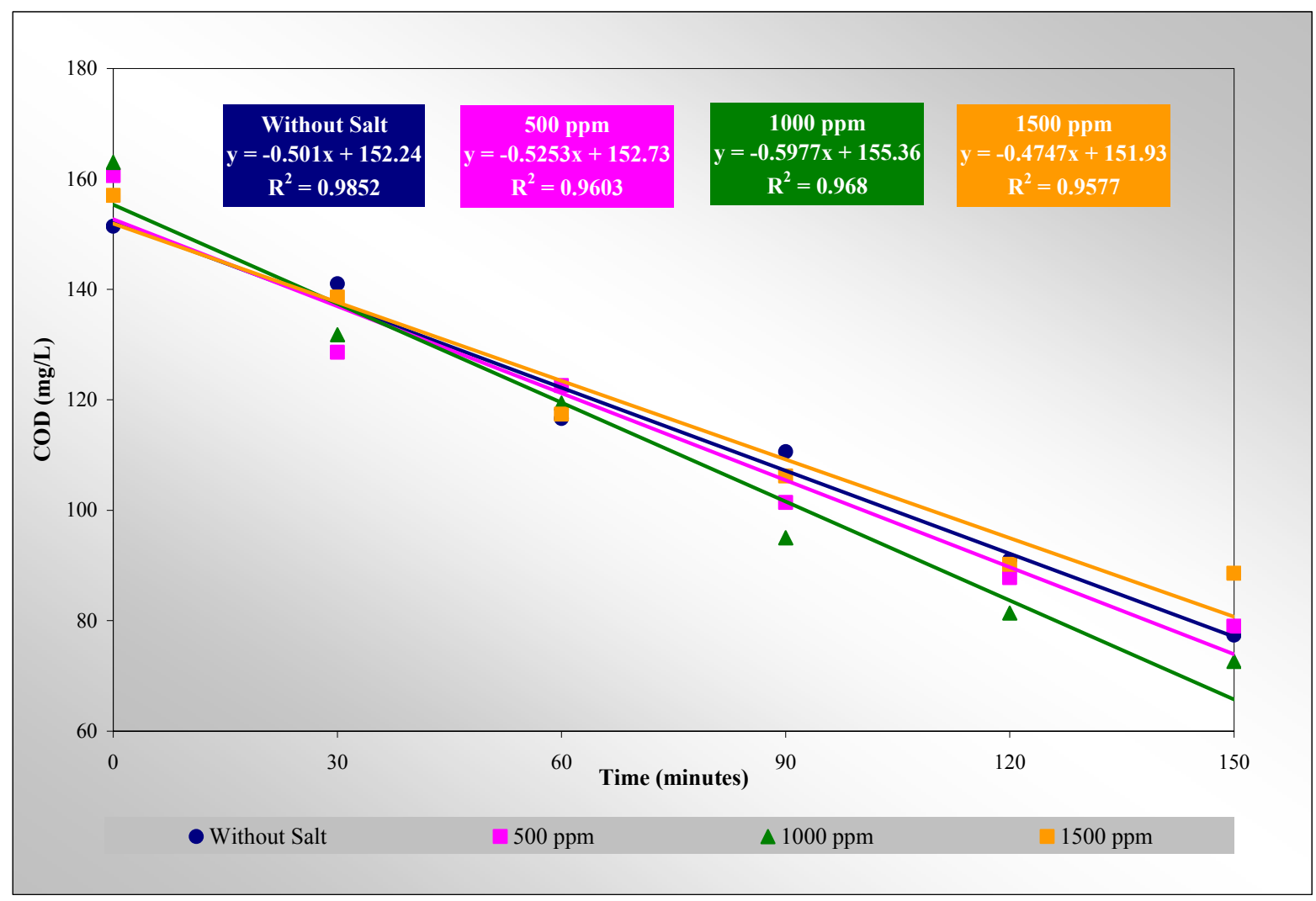

Figure 4-5: COD Stabilization - Regression Analysis

Note: $90 \mathrm{mg} / \mathrm{L}$ of COD added to the wastewater in the form of Tryptic Sot Broth

It can be seen from Figure 4-5 that the COD concentration in the reactors which were shock loaded with salt declined at the same rate $( \pm 10 \%)$ as the one in which no was salt added. For the maximum concentration of $1500 \mathrm{mg} / \mathrm{L}$, there was very little effect on the stabilization of organic matter with the addition of salt as compared to the control. This indicates that this range of salt concentration did not have any adverse impacts on the ability of the microbial population to oxidize organic matter.

Microbes are known to sustain variations in their external environment by a variety of different mechanisms. One of the ways in which changes in external salt concentration levels are tolerated is a phenomenon known as osmotic tolerance. This tolerance is accomplished by changes in the intracellular ionic strength depending on the ionic strength of the external medium. Microorganisms adjust their internal osmolarity in such as way that it always exceeds 
that of the medium. Changes in external sodium $\left(\mathrm{Na}^{+}\right)$ion concentration is adjusted by varying the intracellular potassium $\left(\mathrm{K}^{+}\right)$ion concentration (Stanier et al., 1987).

The maintenance of osmotic balance is critical for efficient physiological functioning of microbes (Stanier et al., 1987). It seems that the microbial cells studied in these experiments were able to maintain an osmotic balance with their micro environment thereby not allowing high salt concentrations to inhibit their essential metabolic processes.

Moreover, the approximate range of sodium chloride concentration tolerated for growth for non halophiles lies in the range $-0.0-4.0 \% \mathrm{~g} / 100 \mathrm{ml}$ or $0-40,000 \mathrm{mg} / \mathrm{L}$ (Stanier et al., 1987). The salt concentrations at which these experiments were conducted lie well within this range of $\mathrm{NaCl}$ tolerance. This range suggests that the microbial population might also be able to tolerate salinity levels much beyond those used in these experiments. However, the actual impacts of higher salinity levels on microbes need to be tested. The average salt concentration in INDOT truck wash water was $41.2 \mathrm{~g} / \mathrm{L}$, or about 4\% (Alleman et al., 2004). Discharge of this wash water would result in significant dilution to levels that are well below concentrations of concern.

In this study, difficulties were faced in trying to conduct COD measurements for salt concentrations beyond $2000 \mathrm{mg} / \mathrm{L}$ because of chloride interference beyond that level. The interference of chloride could be inhibited by addition of excess mercuric sulfate up to a concentration of $5000 \mathrm{mg} / \mathrm{L}$, as long as a 10: 1 weight ratio of mercuric sulfate to chloride was maintained. But this would make the process complicated and the results obtained by this method might not be accurate and reliable. For further research on this topic, it is suggested that for studying the effects of salt concentrations beyond $2000 \mathrm{mg} / \mathrm{L}$ on organic matter stabilization, total organic carbon (TOC) measurements could be conducted instead of COD. Also, measurements of concentration of mixed liquor suspended solids (MLSS) under varying levels of salt concentrations might provide a more direct insight on the health and growth conditions of the activated sludge biomass. The impact that salinity has on nutrient removal efficiency of conditioned activated sludge waste also remains to be explored. 


\subsection{TURBIDITY REDUCTION RATE IMPACT RESULTS}

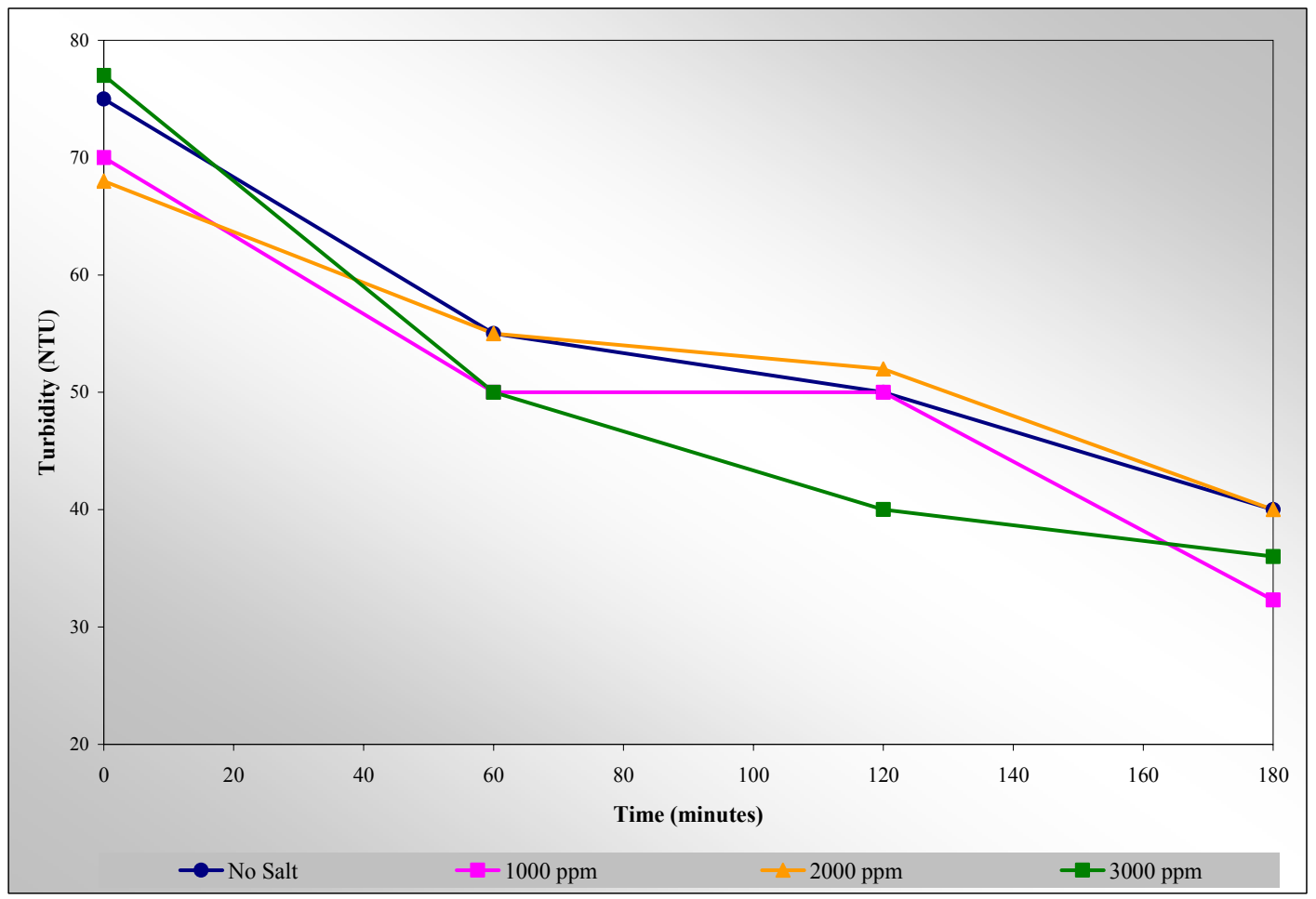

Figure 4-6: Effect of Low Salinity on Turbidity 


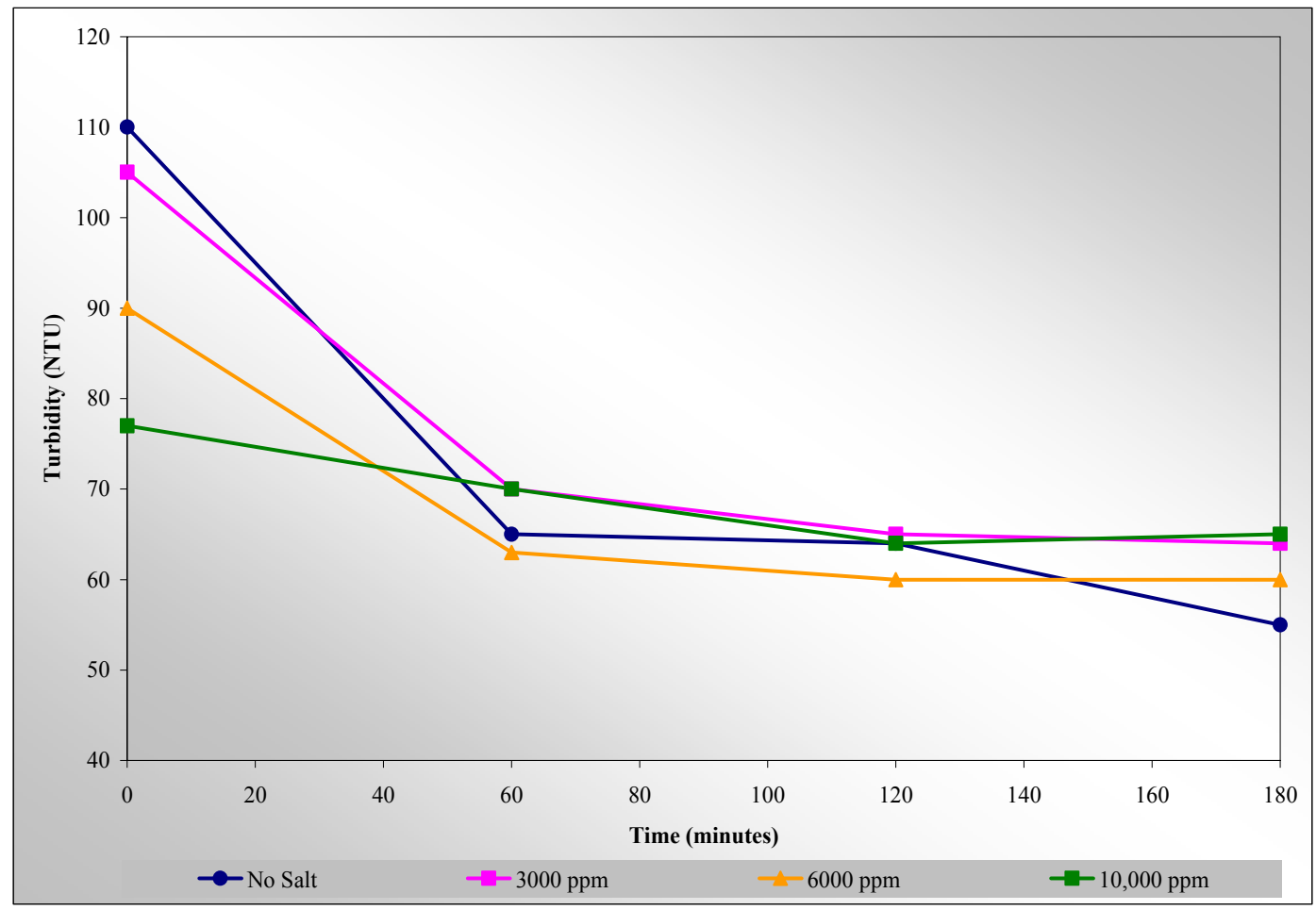

Figure 4-7: Effect of High Salinity on Turbidity

Figures 4-6 and 4-7, illustrate that the turbidity decreases with time for all the samples. As time progresses, particles get more time to collide with one another and form flocs. From Figure 4-6, it can be observed that reduction in turbidity is not much different at 1000 and $2000 \mathrm{mg} / \mathrm{L}$ salt concentrations as compared to the scenario when no salt has been added. As salinity level reaches $3000 \mathrm{mg} / \mathrm{L}$, there is a faster decline in turbidity levels.

For the high salinity range, it can be seen from Figure 4-7 that for the first time point (for the first time point, samples were taken within 10 minutes of each other); there is almost an instantaneous drop in turbidity. This could be explained from the theory of double layer compression and hydrophobic bonding as described earlier. As the concentration of sodium ion increases in solution, it decreases the thickness of the double layer and helps to bring particles of same charge closer. Thus, it helps in faster and better floc formation which enhances the settleability of the colloidal matter. This leads to a faster decrease in turbidity. 
As an extension to these experiments, turbidity measurements could be taken at levels beyond the critical salinity level i.e.1- $2 \% \mathrm{w} / \mathrm{w}$ i.e. $10,000 \mathrm{mg} / \mathrm{L}-20,000 \mathrm{mg} / \mathrm{L}$, to see if there is any increase in turbidity as compared to the control beyond that limit and whether the ion exchange phenomena, as explained earlier, actually occurs. 


\subsection{CYANIDE LEVELS PRESENT IN INDOT'S SALTS}

Table 4-3: Experimental Results for Cyanide

\begin{tabular}{|l|c|c|c|}
\hline \multicolumn{1}{|c|}{ Sample / Salt Location } & $\begin{array}{c}\text { Total Cyanide } \\
(\mathbf{m g} / \mathbf{L})\end{array}$ & $\begin{array}{c}\text { Amenable } \\
\text { Cyanide (mg/L) }\end{array}$ & $\begin{array}{c}\text { Total Cyanide after } \\
\mathbf{U V} \text { exposure (mg/L) }\end{array}$ \\
\hline Lafayette & 4.4 & 0.42 & 3.6 \\
\hline West Lafayette & 0.3 & 0.42 & 0.59 \\
\hline
\end{tabular}

Table 4-4: Mass of Inerts in Samples Given for Testing

\begin{tabular}{|l|c|c|}
\hline \multicolumn{1}{|c|}{ Sample / Salt Location } & $\begin{array}{c}\text { Inerts (gms) } \\
\text { (in } \mathbf{1} \mathbf{L} \text { of amenable } \\
\text { cyanide sample) }\end{array}$ & $\begin{array}{c}\text { Inerts (gms) } \\
\text { (in } \mathbf{1} \mathbf{L} \text { of total cyanide } \\
\text { sample; w/o UV exposure) }\end{array}$ \\
\hline Lafayette & 34.12 & 15.25 \\
\hline West Lafayette & 16.92 & 6.01 \\
\hline
\end{tabular}

It was expected that exposure to UV radiation would cause cyanide complexes to break up into free cyanide and this would lead to an increase in its concentration. But it is seen from the Table 4-1 that the effect of exposure to UV radiation does not show any increase in total cyanide levels for any of the salts. In fact there is a decrease in the measured concentration; this might be because of the difference in homogeneity of the two samples. Moreover, the method of exposing the samples to UV radiation was crude and this might have caused the difference in readings.

The reports obtained from Heritage Laboratories show that Lafayette road salt has high levels of both total $(4.4 \mathrm{mg} / \mathrm{L})$ and amenable cyanide $(0.42 \mathrm{mg} / \mathrm{L})$. It is assumed that the concentration of salt in undiluted salt wash water is $\sim \mathbf{4 0} \mathbf{~ g m s} / \mathbf{L}$ (175 gallons of wash water per truck). However, the concentration of salt used in this study was $100 \mathrm{gms} / \mathbf{L}$. Therefore, the expected cyanide levels (after considering inert solids) in the wash water would be around $4.23 \mathrm{mg} / \mathrm{L}$ and $\mathbf{0 . 4}$ 
$\mathbf{m g} / \mathbf{L}$ for total and amenable cyanide respectively based on an original salt concentration of 40 $\mathrm{gms} / \mathrm{L}$. If this wash water reaches a wastewater treatment plant, the concentration of total and amenable cyanide after dilution should be below the lowest concentration of concern, about 5 $\boldsymbol{\mu g} / \mathbf{L}$. Comparing these values with the limits on total (20- $27 \mu \mathrm{g} / \mathbf{L})$ and amenable cyanide (22 $\mu \mathrm{g} / \mathrm{L}$ for acute aquatic life and $5.2 \mu \mathrm{g} / \mathrm{L}$ for chronic aquatic life), it can be seen that the treatment plants might face some issues in meeting their effluent quality standards for total cyanide under future regulatory scenarios. However, nationally there has already been some examination of the potential environmental effects of both salt and the cyanide based anti-caking agents (Anderson et al., 2000; Langen et al., 2006; Ramakrishna, D.M., and T. Viraraghavan. 2005; Paschka et al., 1999). It would be prudent for INDOT to monitor this research agenda. It is likely that DOTs in heavier snow belt regions such as Minnesota and upstate New York will continue to take lead roles on this issue.

In this research effort, only preliminary analysis to test the cyanide levels was done. The actual fate of cyanide i.e. whether it will be degraded, absorbed, dissociated, or otherwise transformed as it enters and passes through a treatment plant is unknown. However, based on a thorough examination of published literature it seems unlikely that salt or cyanide would affect the physical and biological operations at a wastewater treatment plant. 


\section{Conclusion}

From the theoretical and experimental research done as a part of this study, the following conclusions can be drawn:

- The stabilization of organic matter is not adversely affected by salinity levels until 1500 $\mathrm{mg} / \mathrm{L}$.

- There seems to be little or no impact on the rate of decline in turbidity below $3000 \mathrm{mg} / \mathrm{L}$ of salt concentration. Salinity levels in the range of $3000-10,000 \mathrm{mg} / \mathrm{L}$ enhance the colloidal settleablity of activated sludge and result in faster reduction in turbidity.

- Levels of cyanide from anti-caking agents in road salt have caused no documented adverse environmental impacts. However, this is an issue of ongoing concern nationally and INDOT should remain cognizant of DOT practices in snow belt states, as well as potential modifications to federal regulations.

- Low salt concentrations (as low as $0-4 \%$ ) are found to have a positive to no effect on the oxygen uptake rates of the tested samples for a minimum testing duration of 6 hours which is equivalent to the minimum hydraulic retention time on aeration tanks.

- The average salt concentration in concentrated truck wash water is approximately $4 \%$. Upon discharge of this wash water to a POTW under a typical scenario the salt concentration would be diluted to a negligible concentration of approximately $40 \mathrm{mg} / \mathrm{L}$.

- Higher salt concentrations exceeding $4 \%$ depressed the oxygen uptake rate on the tested samples with a $50 \%$ inhibition at concentrations exceeding $6 \%$. Salt concentrations as high as $8 \%$ resulted in approx. 55\% inhibition however these high salt concentrations are not likely to occur in treatment plant due to wash water. Higher salt concentrations cause plasmolysis and thus compromise the performance of the biological treatment operations.

Thus, if low salinity salt wash wastewater (up to $1500 \mathrm{mg} / \mathrm{L}$ after dilution) is discharged into the local POTWs for treatment; it would not have any adverse effect on the efficiency of the treatment plants as far as stabilization of organic matter and sludge settleability are concerned. In fact higher salinity levels (up to $10,000 \mathrm{mg} / \mathrm{L}$ ) might even result in faster and better turbidity reductions. 
References

- Alleman, J.E., Partridge, B.K., and L. Yeung. 2004. Innovative Environmental Management of Winter Salt Runoff Problems at INDOT Yards. Final Report, Joint Transportation Research Program, Purdue University with the Indiana Department of Highways and Federal Highway Administration. FHWA/IN/JTRP 2001/27.

- Anderson, J., Estabrooks, T., and J. McDonnell. 2000. Duluth Metropolitan Area Streams Snowmelt Runoff Study. Minnesota Pollution Control Agency.

- APH, AWWA, WEF (1995). "Standard Methods for the Examination of Water and Wastewater". $19^{\text {th }}$ edn. Am. Publ. Hlth. Assoc., Washington D.C.

- AWWA (1999). “Water Quality and Treatment: A Handbook of Community Water Supplies”. $5^{\text {th }}$ edn. McGraw Hill Inc., USA.

- Chen, G., Wong, M., Okabe, S. Watanabe, Y. (2003). "Dynamic response of nitrifying activated sludge batch culture to increased chloride concentration". Water research 37 (2003) $3125-3135$.

- Downey, D.A. 2006. Personal Communication to L. Nies. Mr. Downey is the Operations Supervisor, Wastewater Treatment Utility, City of West Lafayette, Indiana.

- Gharsallah, N., Khannous, L., Souissi, N. and Nasri, M. (2002). "Biological Treatment of Saline Wastewater from Marine-Products Processing Factories by a Fixed-Bed Reactor". Journal of Chemical Technology and Biotechnology 77:865-870 (online: 2002), 0268$2575 / 2002$.

- Hamoda, M.F. and Al-Attar, I.M.S. (1995). "Effects of High Sodium Chloride Concentration on Activated Sludge Treatment”. Wat. Sci. Tech. 31 (9), 61-72.

- Langen, T.A., Twiss, M., Young, T., Janoyan, K., Stager, J.C., Osso Jr., J., Prutzman, H., and B. Green. 2006. Environmental Impacts of Winter Road Management at the Cascade Lakes and Chapel Pond - Final Report. Clarkson Center for the Environment, Clarkson University, Potsdam, New York.

- Lee, D. and Jean, D. (1999). "Effects of Salinity on Expression Dewatering of Waste Activated Sludge”. J.Colloid Interf. Sci. 215, 443-445.

- Metcalf and Eddy (1991). “Wastewater Engineering: Treatment, Disposal, Reuse”. $3^{\text {rd }}$ edn. Tata McGraw Hill, India.

- Mrafkova, L., Goi, D., Gallo, V. and Colussi, I. (2003). "Preliminary Evaluation of Inhibitory Effect of Some Substances on Aerobic and Anaerobic Plant Biomass". Chem. Biochem. Eng. Q. 17 (3) 243 - 247 (2003). 
- Nirmalakhandan, N., Sun, B., Arulgnanedran, V. J., Mohsin, M., Wang, X. H., Prakash, J. and Hall, N. (1994). "Analyzing and Modeling Toxicity of Mixtures of Organic Chemicals To Microorganisms”. Wat. Sci. Tech. Vol. 30, No. 10, pp. 870 96, 1994.

- Nugul, I., Keller, J. and Blackall, L.L. (1999). "Biological Nutrient Removal Efficiency of Saline Wastewater". Wat. Sci. Tech. 39 (6), 183-190.

- Paschka, M., R. Ghosh, and D. Dzombak. 1999. Potential water-quality effects from iron cyanide anticaking agents in road salt. Water Environment Research. 71(6):1235-1239.

- Ramakrishna, D.M., and T. Viraraghavan. 2005. Environmental Impact of Chemical Deicers - A Review. Water, Air, and Soil Pollution. 166: 49-63.

- Rennert, T. and T. Mansfeldt. 2005. Iron-cyanide complexes in soil under varying redox conditions: speciation, solubility and modeling. European Journal of Soil Science, 56:527-536.

- Roš, Milenko (1993). "Respirometry of Activated Sludge". Technomic Publishing Co., Inc., Lancaster, PA

- Rozich, Alan F. and Gaudy, Jr. Anthony F. (1992). "Design and Operation of Activated Sludge Process Using Respirometry”. Lewis Publishers, Chelsa, MI

- Salvadó, H., Mas, M., Menedez, S. and Gracia, M. P. (2001). "Effect of Shock Loads of Salt on Protozoan Communities of Activated Sludge”. Act Protozool. (2001). 40:177 - 185

- Panswad, T. and Anan, C. (1999). "Impact of High Chloride Wastewater on an Anaerobic / Anoxic / Aerobic Process With and Without Inoculation of Chloride Acclimated Seeds". Wat. Res. 33 (5), 1165-1172.

- Petersen, B., Gernaey, K., Ottoy, J. and Vanrolleghem, P. (2002). “Application of biosensors in wastewater treatment".

- Ritvo, G., Dassa, O. and Kochba M. (2003). "Salinity and pH effect on the colloidal properties of suspended particles in super intensive aquaculture systems". Aquaculture 218, 379- 386.

- Stanier, R., Ingraham, J.L, Wheelis, M.L. and Painter, P.R. (1987). "General Microbiology”. MacMillan Education Ltd., Hong Kong.

- Theis, T.L., Young, T.C., Huang, M. and Knutsen, K.C. (1994). "Leachate Characteristics and Composition of Cyanide-Bearing Wastes from Manufactured Gas Plants”. Environ. Sci. Technol. 28, 99-106.

- Transportation Research Board, National Research Council (1991). "Highway Deicing: Comparing Salt and Calcium Magnesium Acetate". Special Report 235. (http://gulliver.trb.org/publications/sr/sr235.html) 
- Vanrolleghem, P. A., (2002). "Principles of Respirometry in Activated Sludge Wastewater Treatment". Universitei Gent, Department of Applied mathematics, biometrics and process control. WWW: http://biomath.rug.ac.be 